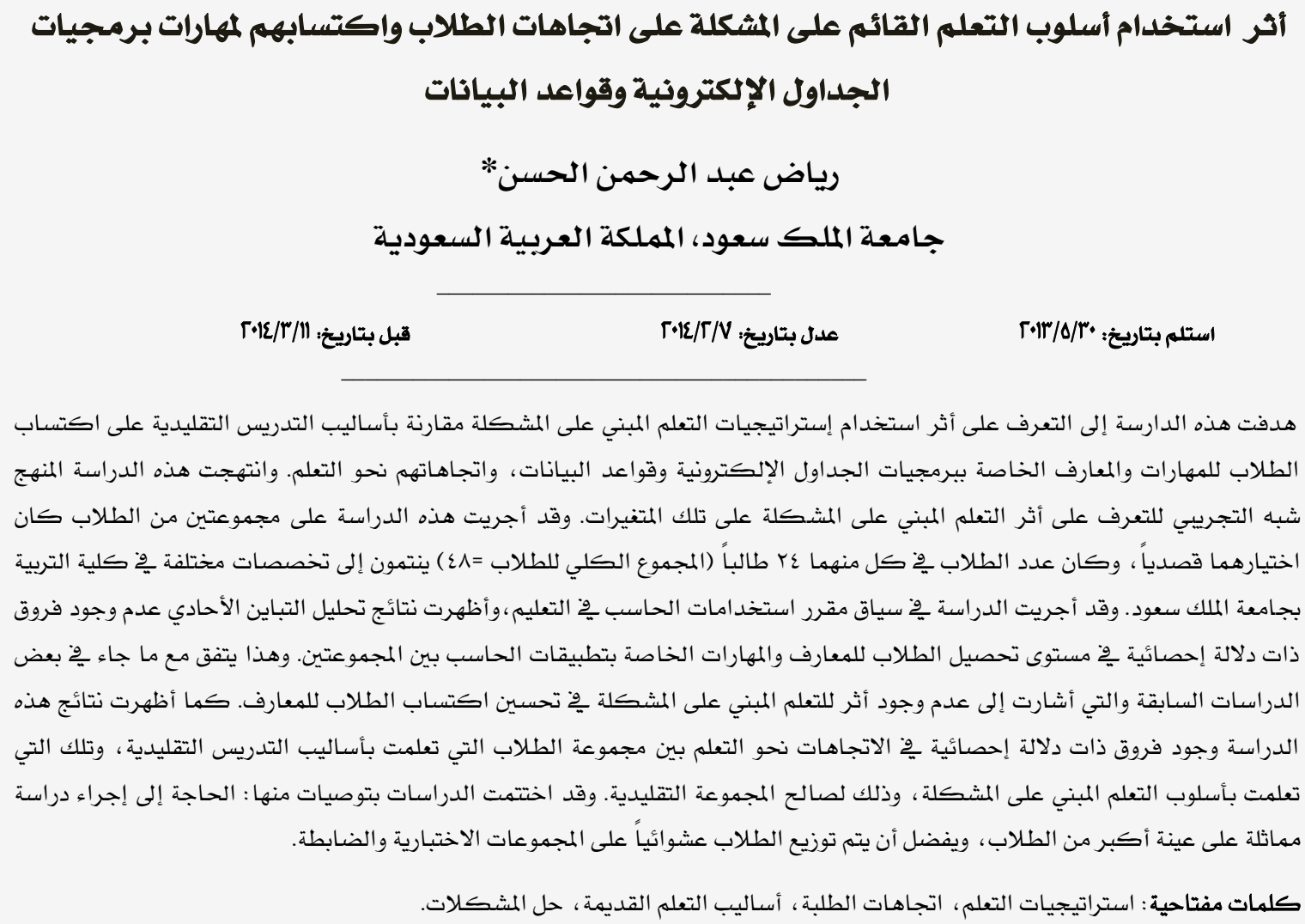

\title{
The Effect of Problem-Based Learning Strategies on Students' Attitudes and Their Acquisition of Database and Spreadsheets Skills and Knowledge
}

Riyadh A. Alhassan*

King Saud University, kingdom of Saudi Arabia

The purpose of this study was to examine the effect of problem-based learning as opposed to traditional learning method on students' attitudes and acquisition of computer application skills and knowledge (database applications, and spreadsheet applications). The study followed a quasi-experimental design to identify the effect of problem-based learning on the previous variables. The study sample was purposely selected and consisted of 48 students enrolled in two sections of an educational computing course offered by the college of education. Analysis of variance (ANOVA) did not reveal any significant differences between the problem-based group and the traditional group in computer application knowledge and skill acquisition. This finding was in agreement with other research finding that showed no significant effect for problembased learning on knowledge and skill achievement. However, ANOVA revealed significant differences in students' attitudes toward learning in favor of the traditional group. The study concluded with several recommendations, among which was the need to replicate the current study with a larger sample size, with randomly selected subjects.

Keywords: Learning strategies, students' attitudes, traditional learning method, problem solving.

*alhassan@ksu.edu.sa 
قصدوراً في نبنـي هذا النوع من إسـتراتيجيات التهله

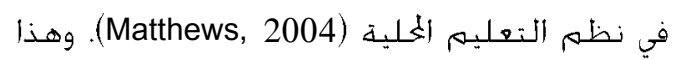

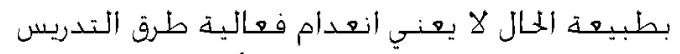

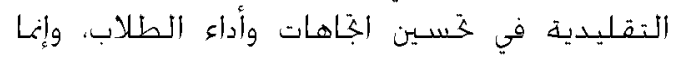

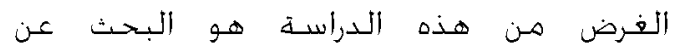

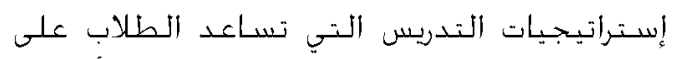

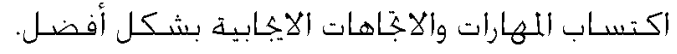

$$
\text { التعلم المبني على المشكلة }
$$

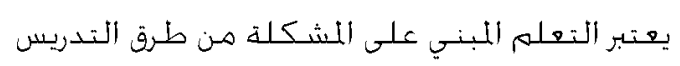

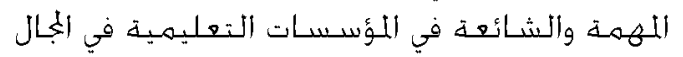

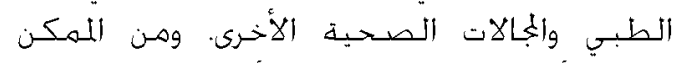

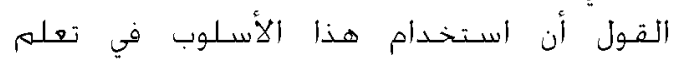

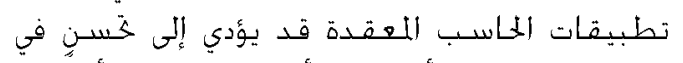

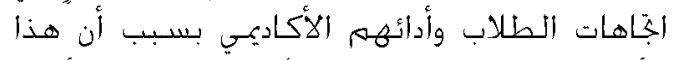

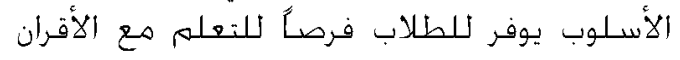

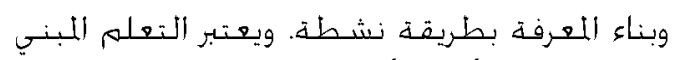

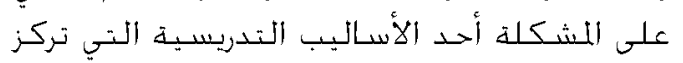

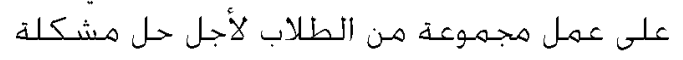

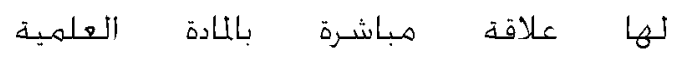
(Boud \& Feletti, 1991)

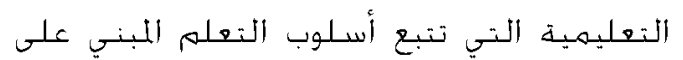

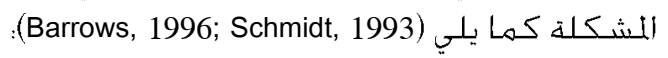

ا. أنها بيئة تعليميذة تتمهحور حول الطالب.

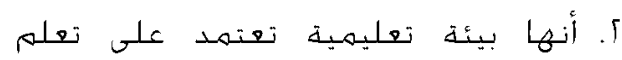

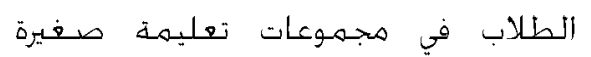
بكونها الملنلهم.

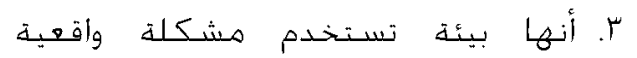

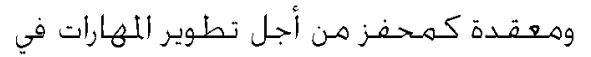

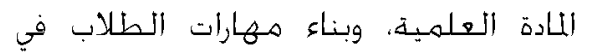
مجال حل المشكلات.

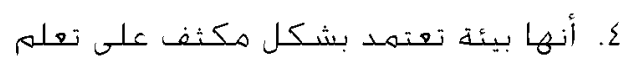

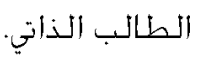

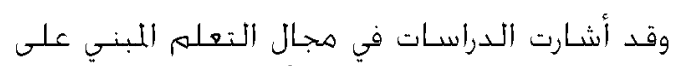

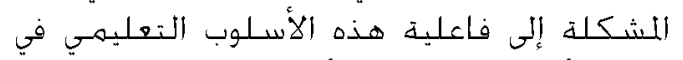

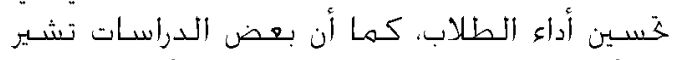

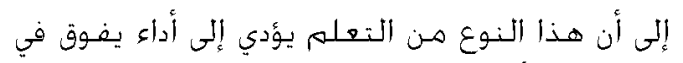

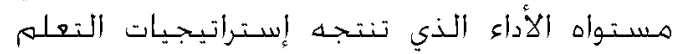
الأخرى Kalishman, \& Snyder, 1993

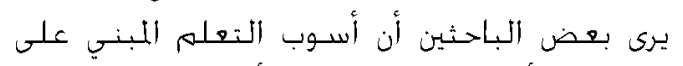

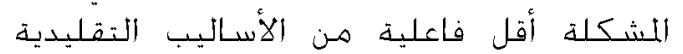

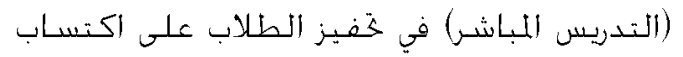
Albanse \& Mitchell, 1993; Vernon \& ) اللهارف
تلعب مهارات الحاسـب الآي دوراً حيوياً في هجتهع

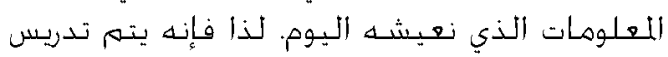

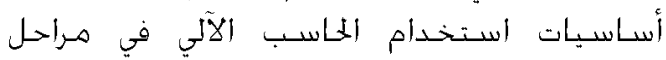

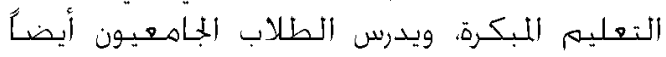
مهارات الخاسب الآلي التي تتعلق بمجال دراستهـمه.

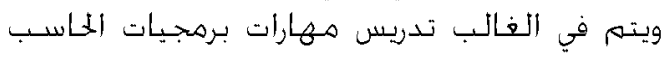

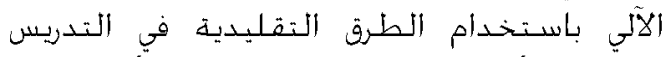

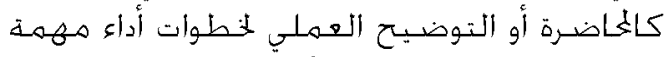

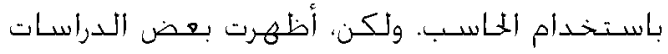
قصهـور الطرق (Rajab, 2007; Matthews, 2004) التقليدية في إيصال معارف ومهارات تطبيقات

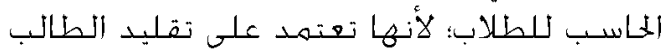

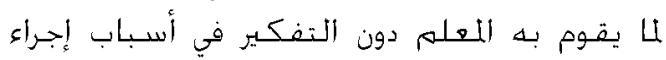

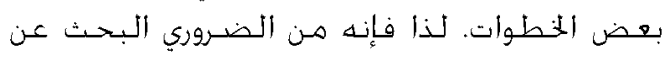

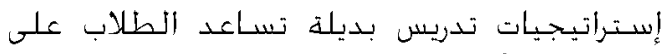

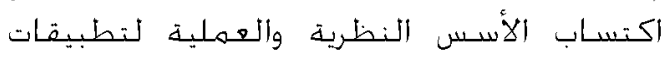

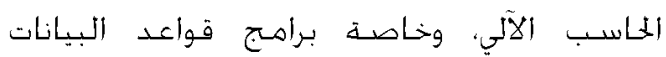

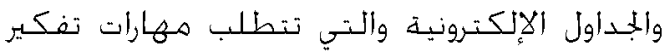

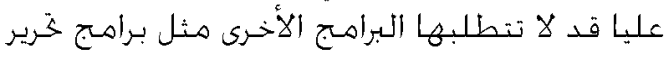

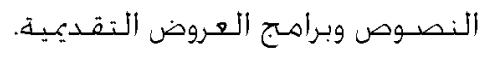

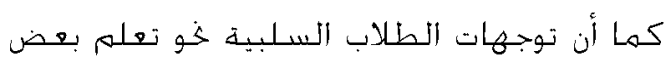

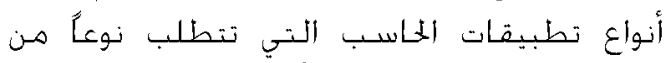

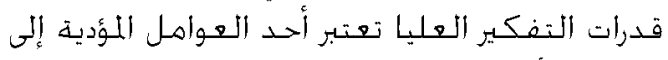

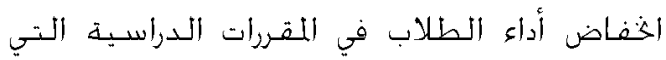

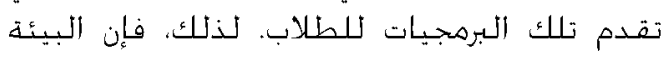

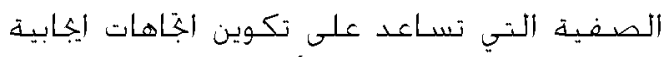

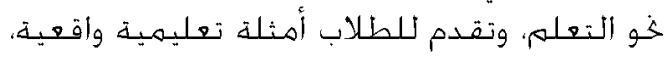

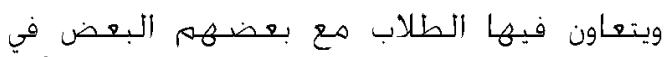

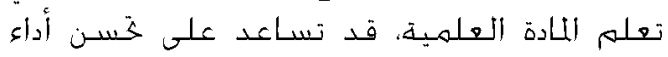

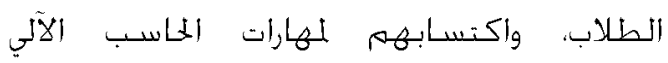
(Rajab, 2007) ويعتبر التهلم اللمبني على المشكلة أنموذجاً (Problem-Based Learning-PBL) تدريسياً يسهى إلى خلق ظـروف صـفية تسـاعد على

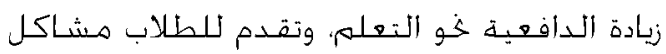

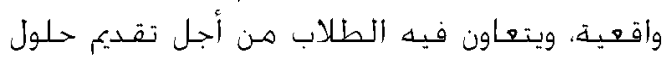
لمشكلة ما. مان وقد فامت الـدراسـة الخالية بمقارنة أثر استخـدام

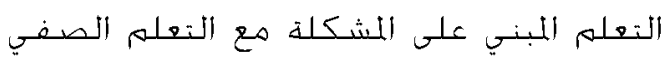

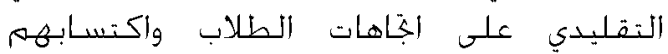

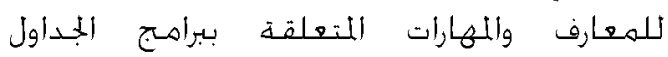

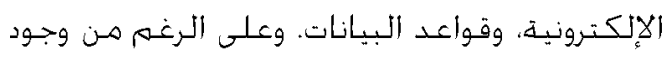

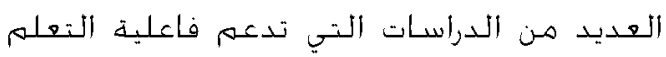

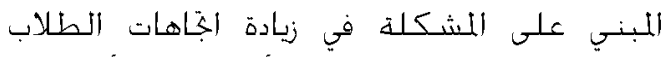

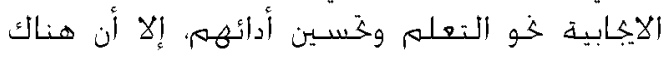


مستخدمين اللعرفة الخاملة والتي اكتسبوها من التئي

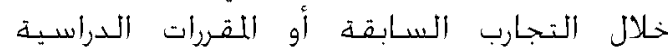

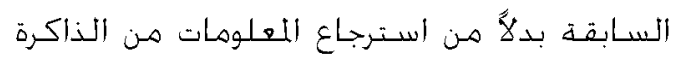

.(Jones, Rasmussen, \& Moffitt, 1997)

أها الأسباب المتعلقة بالدافعية، فتشير إلى الموافز والاجّاهات وكيفية تركيز الطلاب على المشكلة.

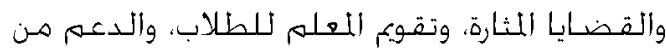

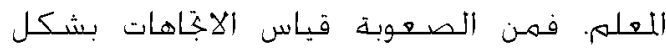

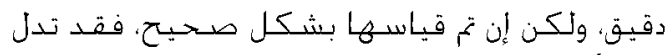

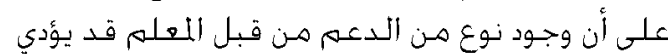

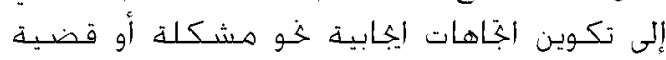

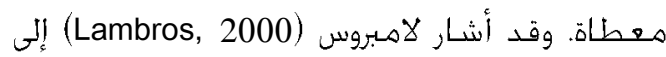

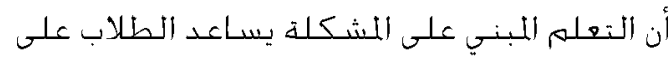

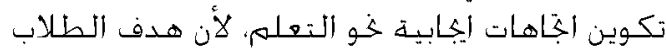

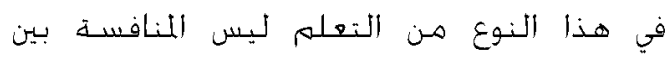

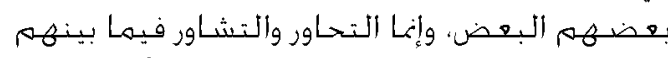

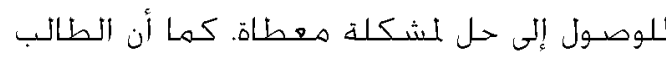

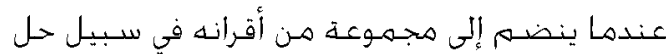

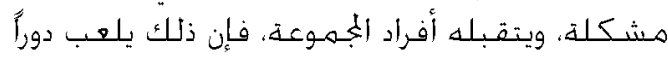

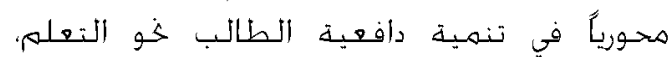
وخاصدة عند تعلم مهارات الحاسب الآلي المعقدة.

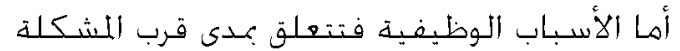

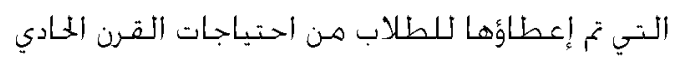

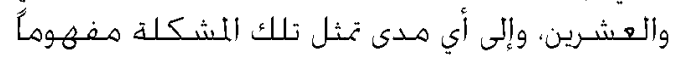

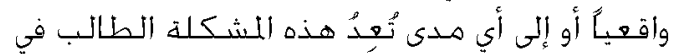

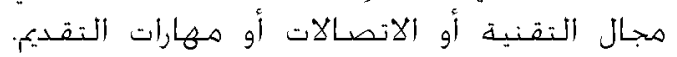

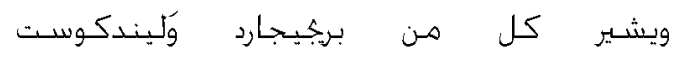
(Birgegard \& Lindquist, 1998)

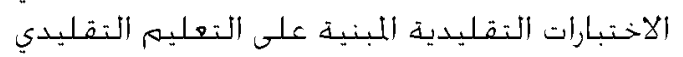

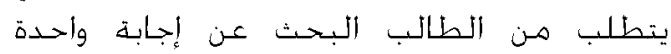

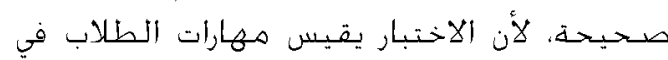

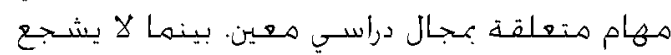

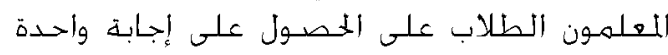

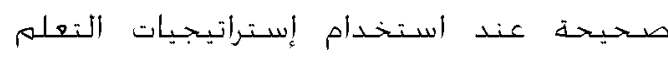

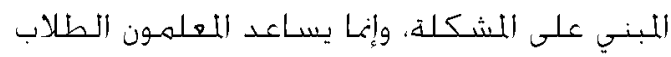

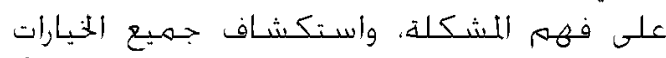

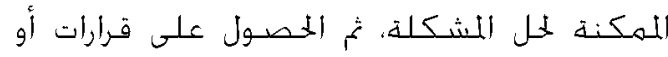

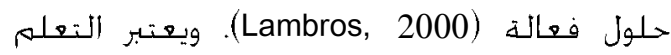

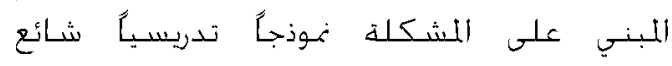

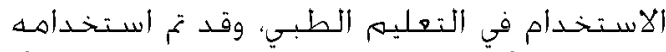

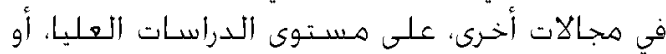

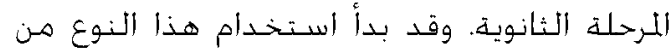

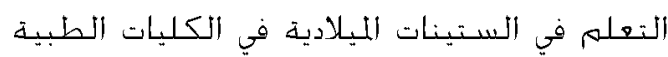

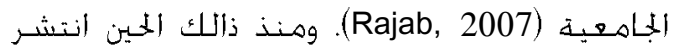

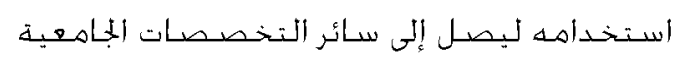

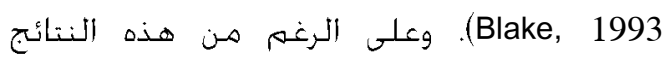

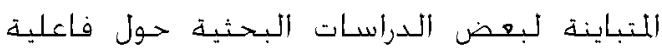

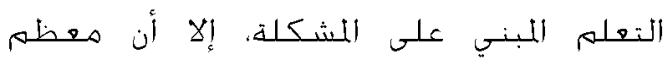

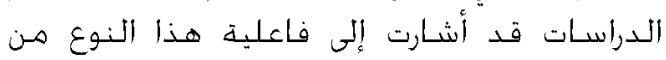

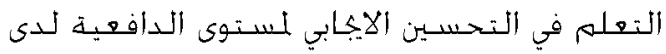

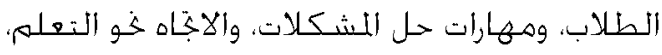

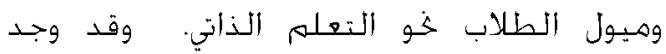
بيدرسـون (Pederson, 2003) أن التعلهم المبني على الني.

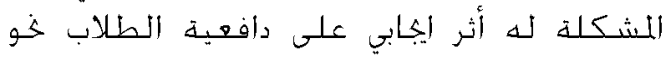

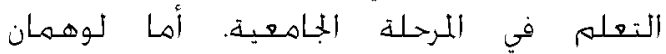
ولوهمان وفيكلستين (Lohman, 2002) فقد أظهرت (Lohman \& Fiklestein, 2000)

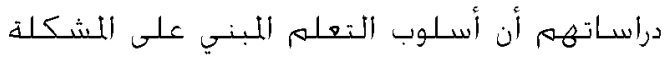

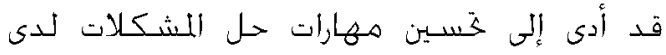

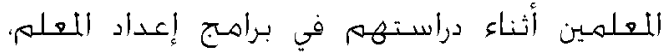
وأطباء الأسنان أثناء فترة دراستههم. أمها بريجيجارد وَّليندكوست (Brigegard \& LindQuist, 1998)

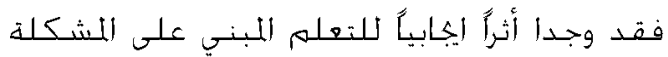

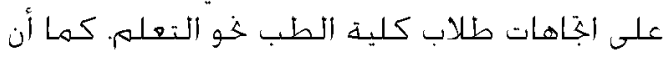

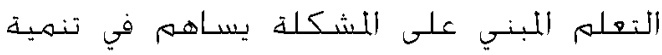

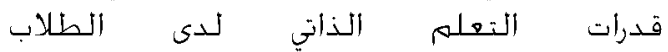
(Shin, Haynes, \& Johnston, 1993; )

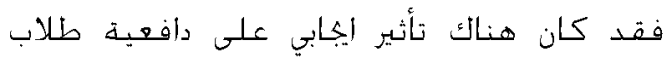

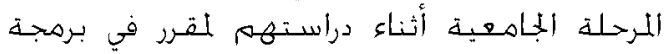

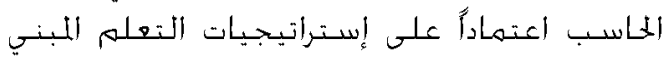
على المشكلة (Dunlap, 2005).

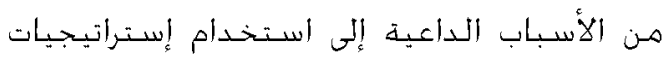

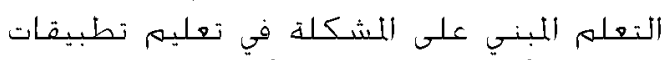

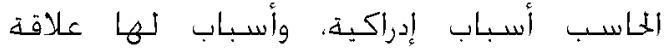

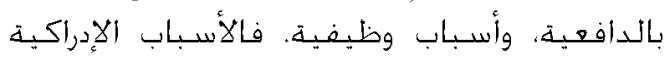

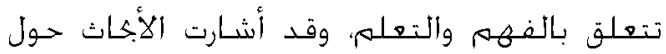

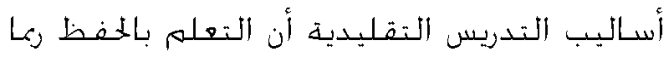
بكون مجديا على اللدى القصير للمهام الرونينية، التهاه

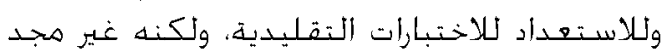

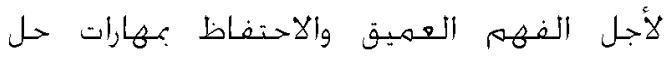

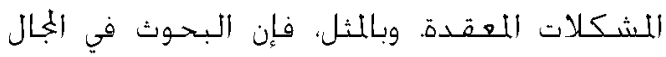

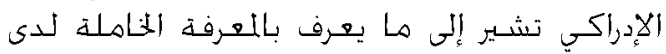

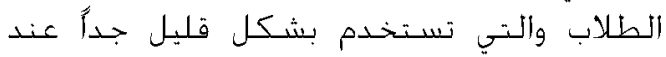

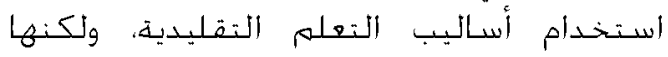

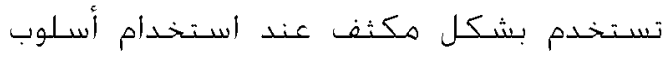

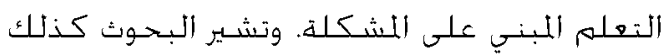

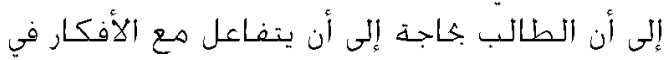

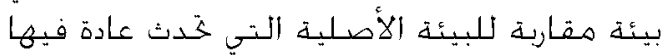

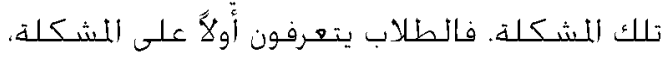

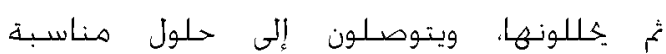


ا. أن الكبار تقودهم الأهداف، ويفضلون المهام

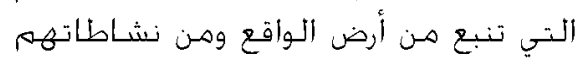

$$
\text { المهنية اليومية. }
$$

أ. بفضل الكبار التحكم مهام التعلهم وأن

يكون لهـم دور مباشر في ذلك.

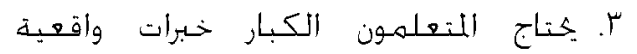

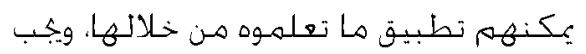

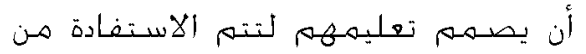

$$
\text { خبراتهم السابقة. }
$$

ك. بفضل الكبار التعلم في بيئة ودبة بتوفر فبها الدعم والتغذية الراجعة البناءة.

ه. يمتاج المتعلمون الكبار إلى التعلم من خلال التهال

$$
\text { مجهوعات صغيرة. }
$$

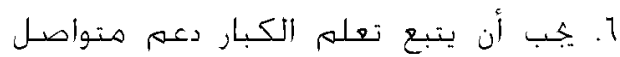

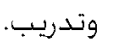

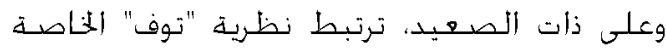

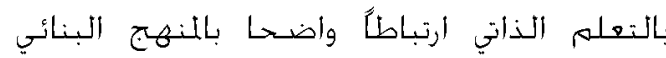

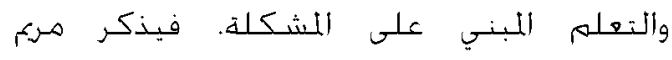
(Marriam, 2001) الطلاب على التعلهم النشط الذي يؤدي إلى وعبهم هونه

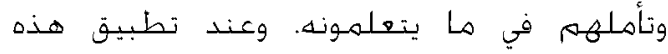

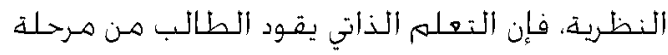
تديد احتياجاته، إلى التعرف على الموارد الني تعينه

$$
\text { على اكتساب المعرفة. }
$$

تظهر كلا النظريتين الواردتين أعلاه جوانب مهمة النها

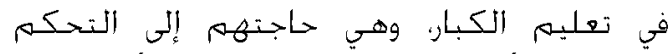

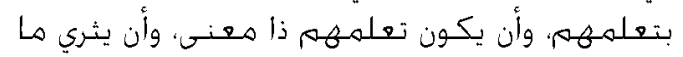
تعلهوا حباتهم العملية، وأن بكون التعلم مفيداً

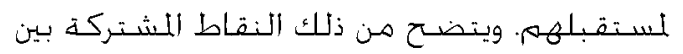
نظريات تعلهم الكبار، والتعلم المبني على دلى المشكلة.

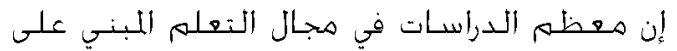

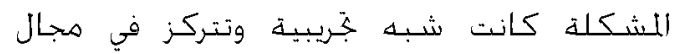

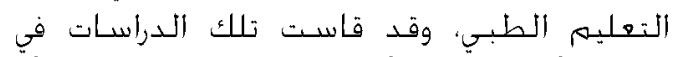

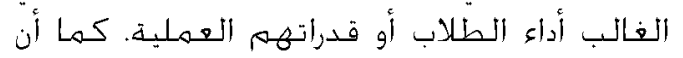

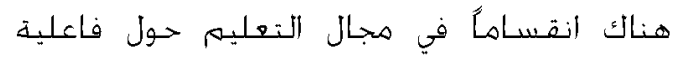

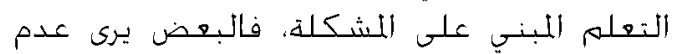
جدوى هذا النوع من التعلهم عند الأنـذ في الاعتبار

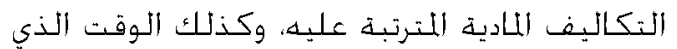

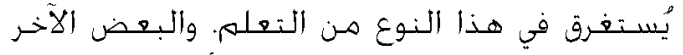

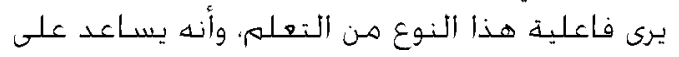

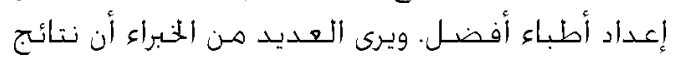

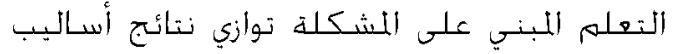

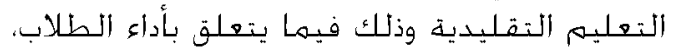

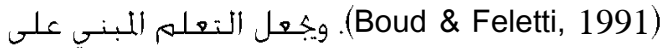

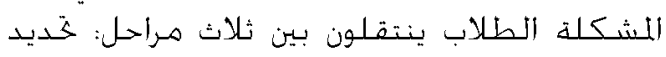

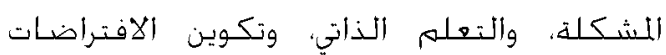

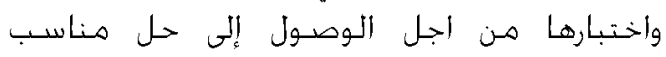

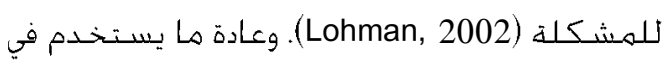

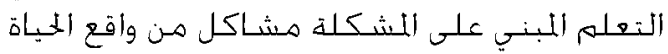

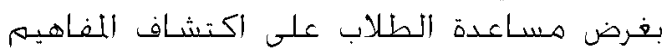

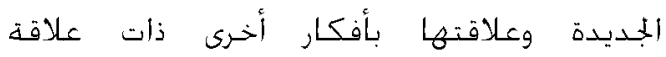

(Allen, Duch, \& Groth, 1996)

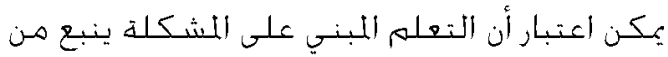

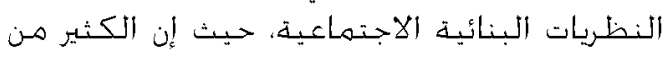

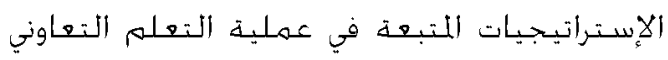

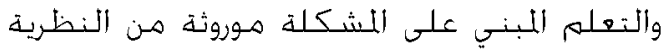
البنائية.

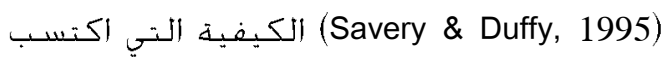

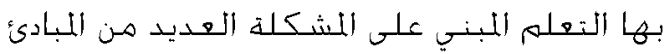

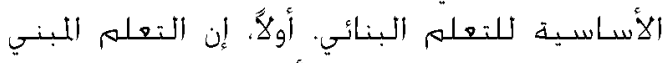

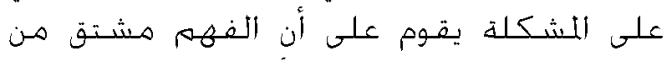

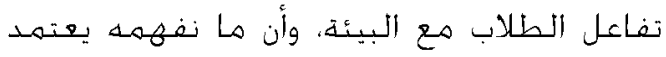

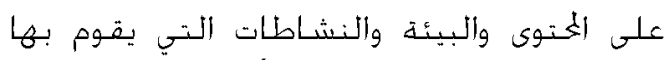

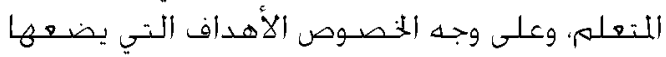

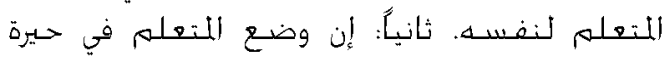

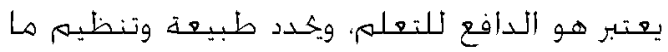

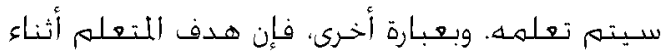

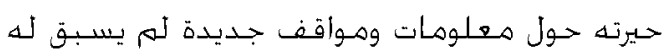

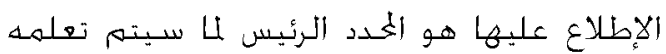
(Savery \& Duffy, 1995)

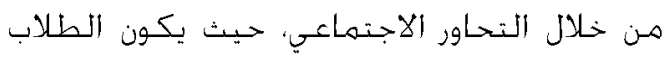

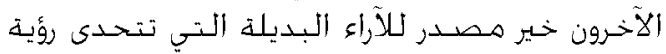

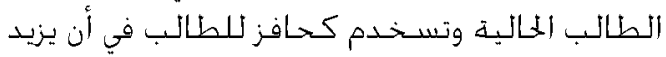

نشاطك في التعلم (Savery \& Duffy, 1995). وعند التركبز على كيفيذ استفلال التعلم المبني

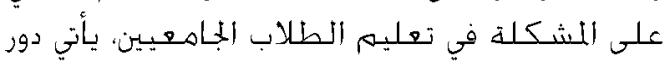

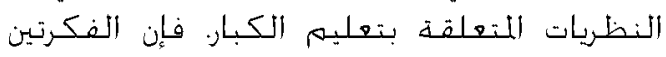

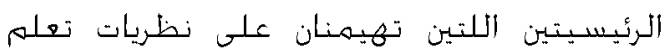

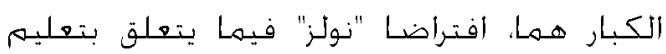

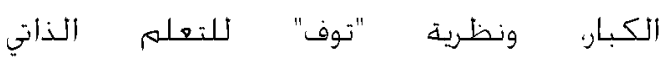

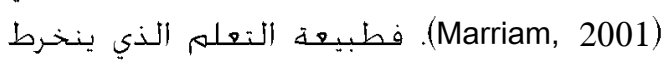

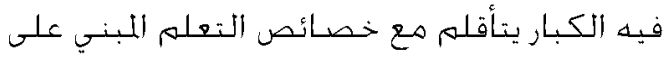

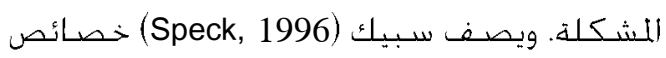

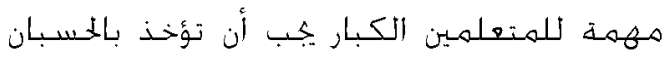

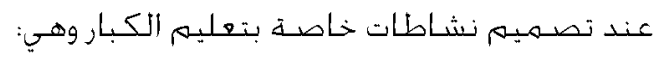




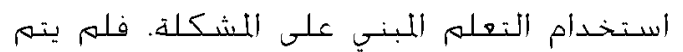

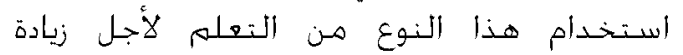

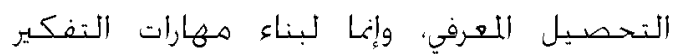

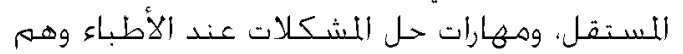

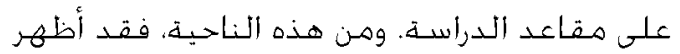

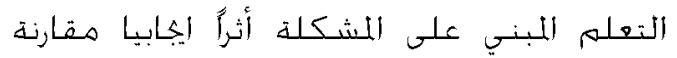

بأساليب التدريس التقليدية (Hmeol, 2004). وهناك العديد هـن المؤشرات التي تشير إلى التأثير

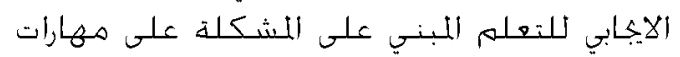

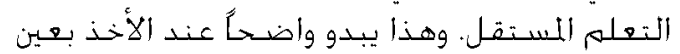

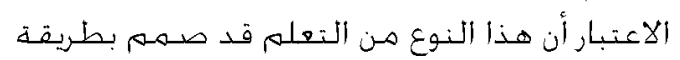

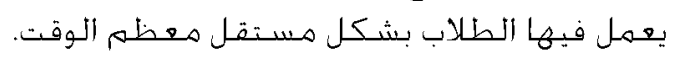

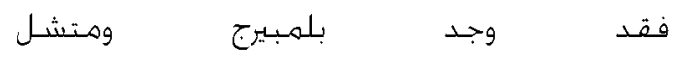
(Blumberg \& Mitchael, 1992) لطلاب كلية الطب أن الطلاب الذين يتعلمون

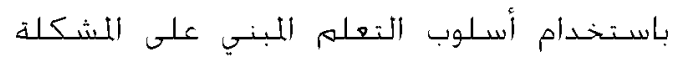

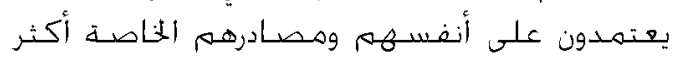

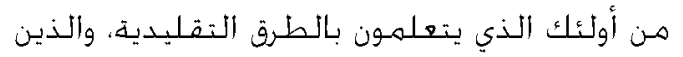

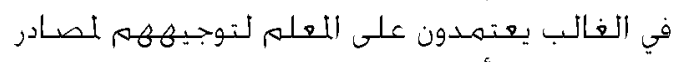

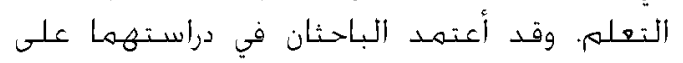

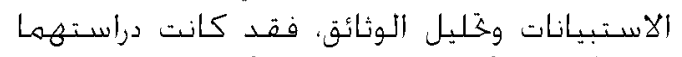

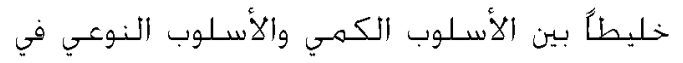

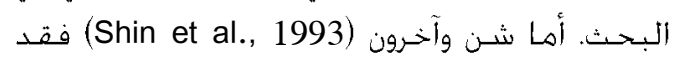

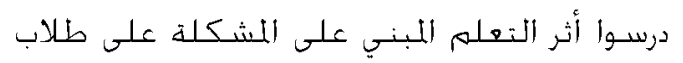
الطب بعد خُرجهم وأخراطهيم في العمل المبل المهني.

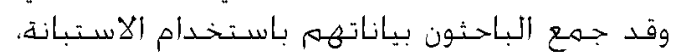

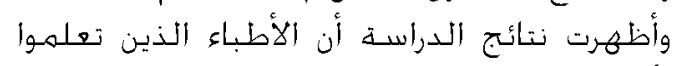

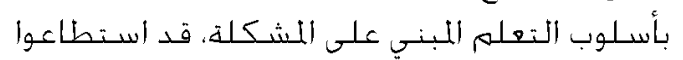

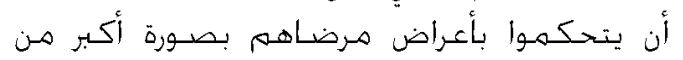

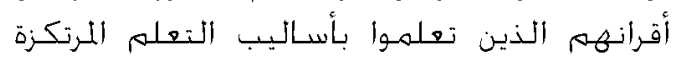

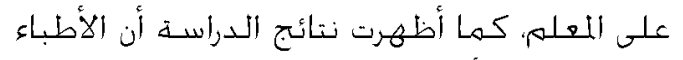

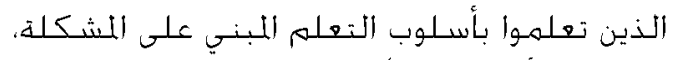

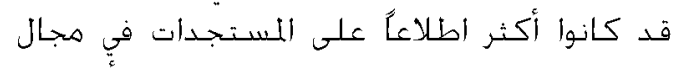

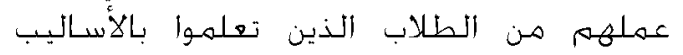

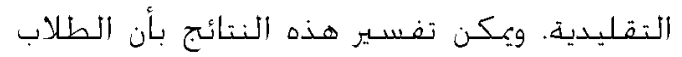

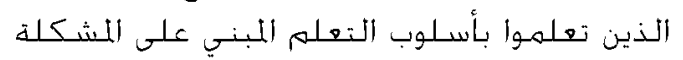

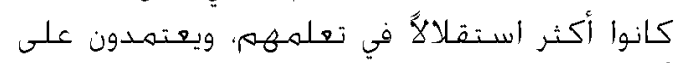

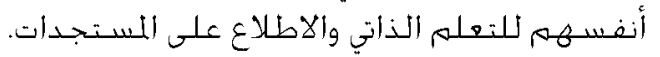

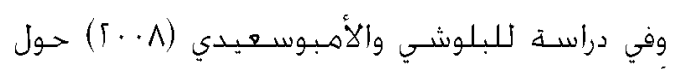

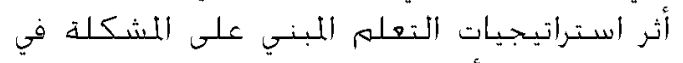

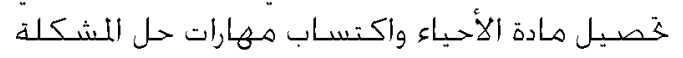

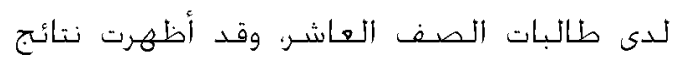

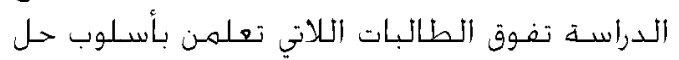

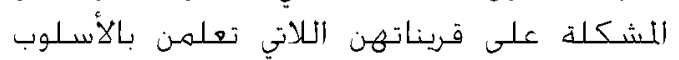

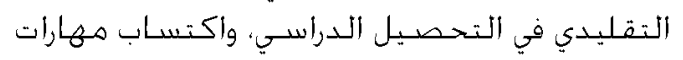

ولكن للتعلم اللبني على المشكلة نتائج إيكابية

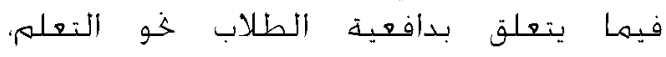

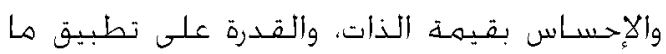

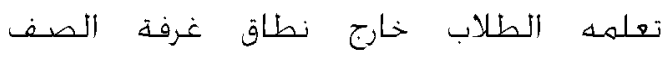
Albanse \& Mitchell, 1993; Boud \& Feletti, )

(1991; Vermon \& Blake, 1993

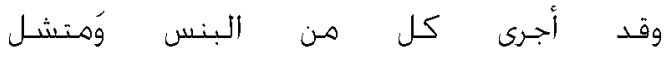
و فرنون وَبليك (Albanse \& Mitchell, 1993) (Vernon \& Blake, 1993) حول الدراسـات في مجال التهله (Meta-analysis)

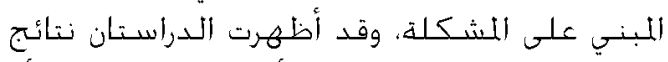

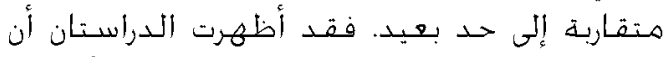

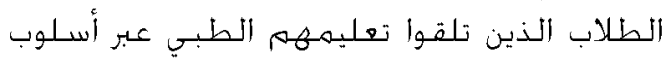

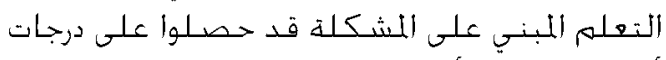

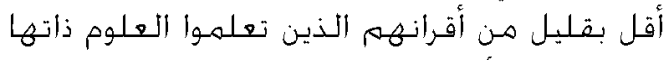

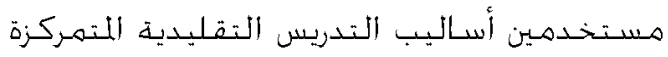

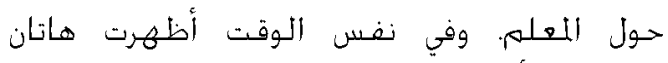

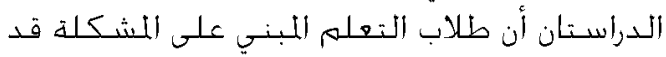

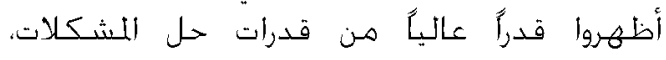
واللهارات الطبية التطبيقية مقارنة بزملائهم الذين تعلمـوا باستخـدام طرق التدريس التقليدية. وفي دراسـة خليل بعدي حـيثة، حلل دوتشـي وآخـرون (Dochy et al., 2003)

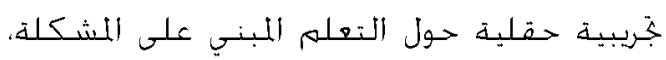

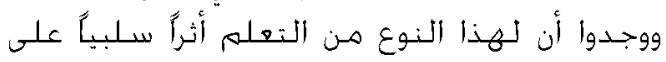

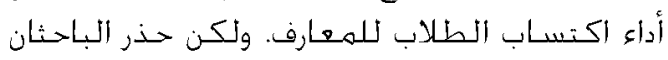

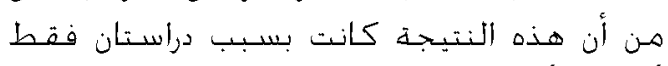

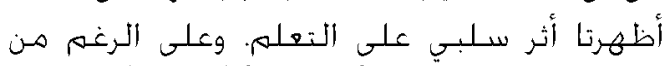

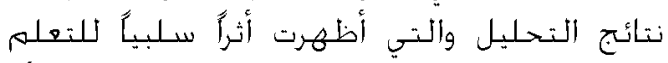

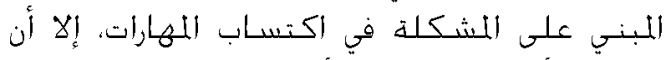

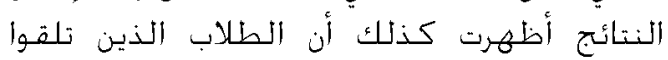

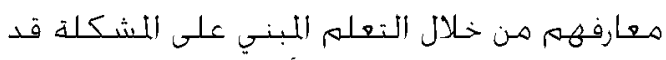

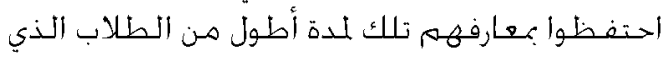

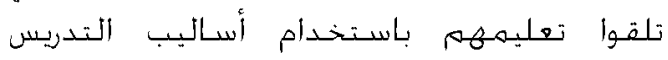

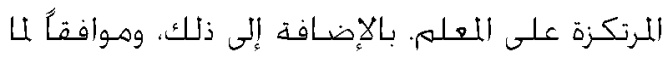

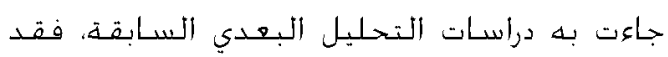

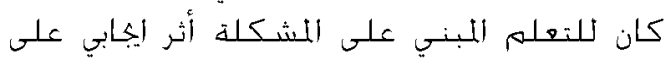

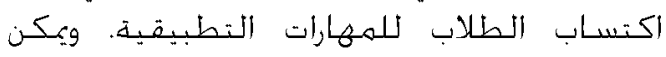

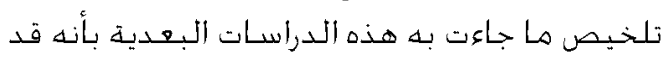

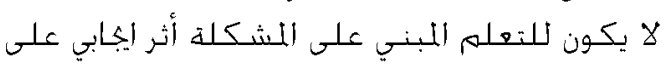

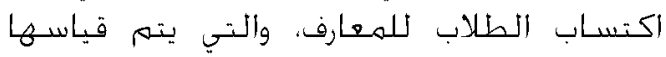

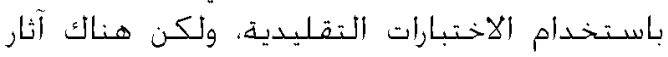

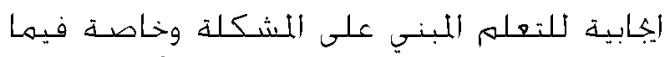

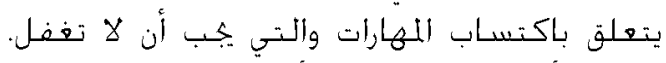

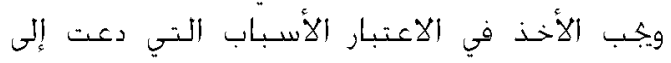




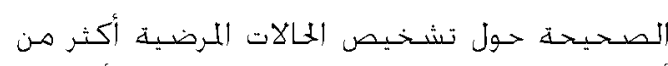

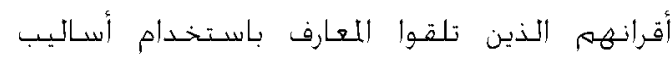
التعلم التقلمبدية.

وقد أظهرت معظم اللدراسات وجهود علاقة ايجابية بين

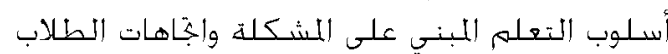

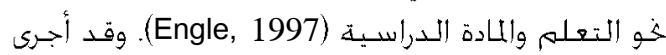

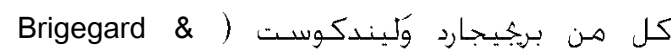
(Lindquist, 1998 فبها استفتاء الطلاب قبل وبعد تطبيق برنامجين

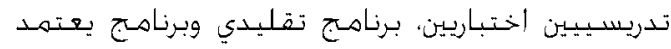

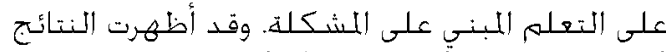

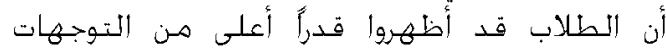

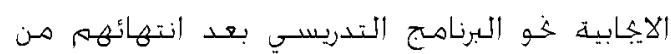

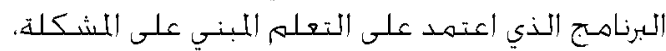

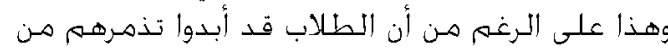

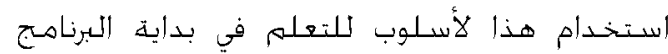

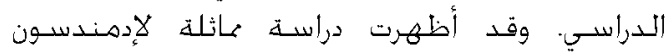
(Edmondson, 1995)

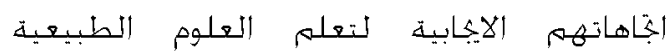

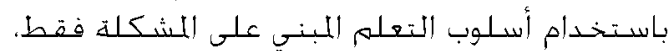

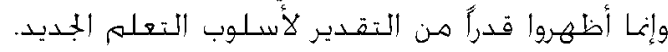

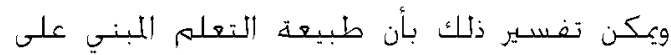

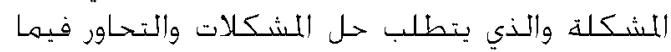

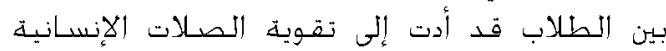
والعلاقات اللاجتماعية بينهمه.

وبوجه عام، فإن الطلاب قد إظهروا اخجاها ايجابيًا

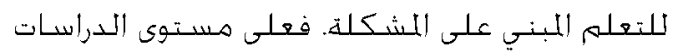

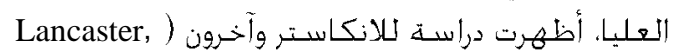

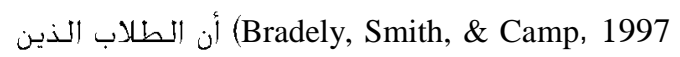

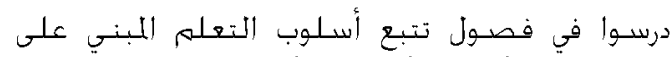

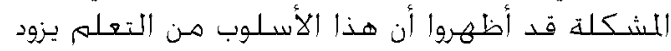

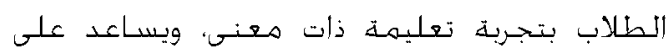

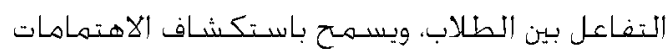

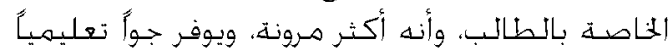

إيكابياً.

التعليق على الدراسـات السـابقة:

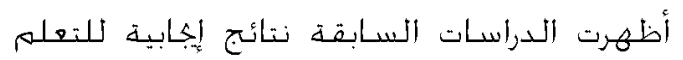

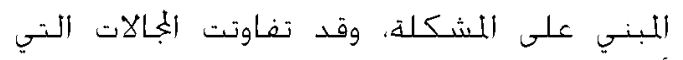

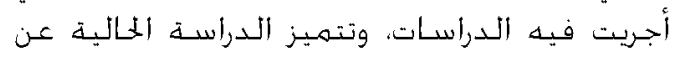

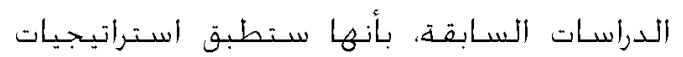

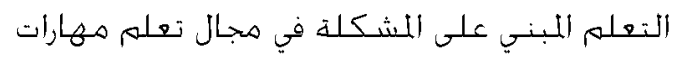

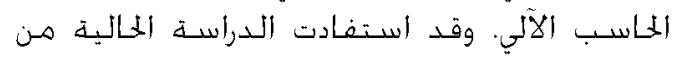

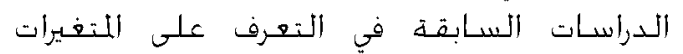

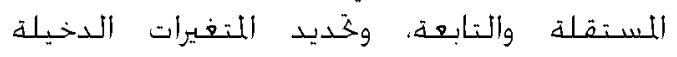

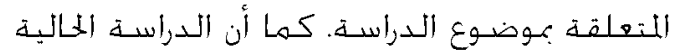

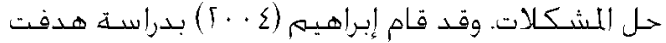

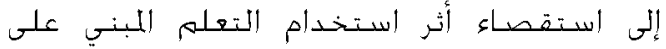

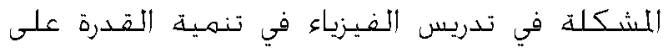

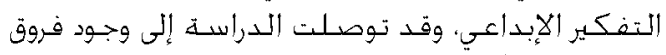

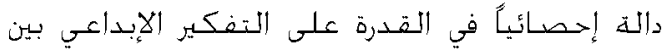

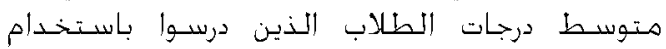

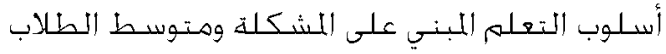

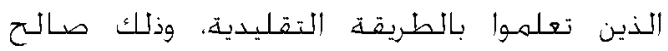

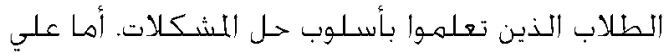

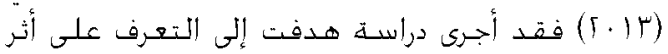

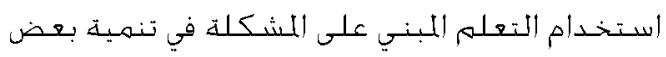

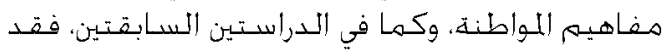

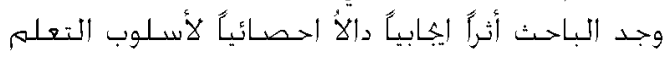

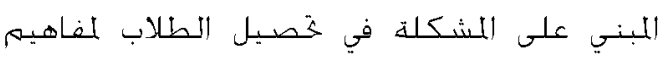
المواطنة.

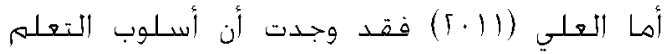

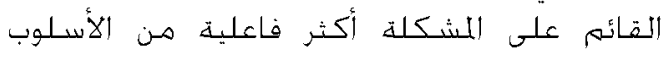

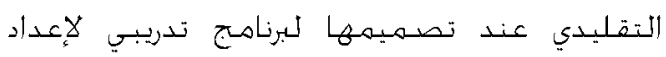

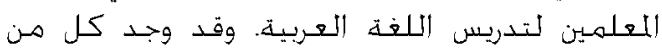

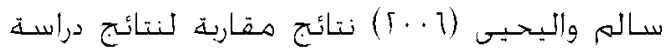

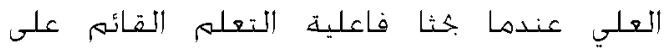

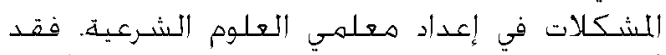

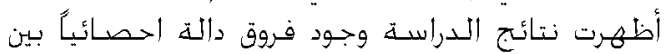

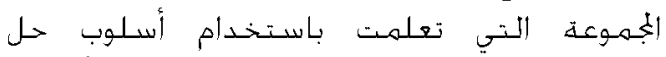

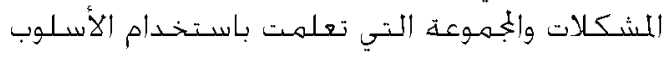

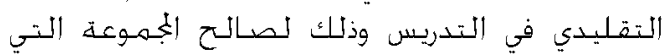

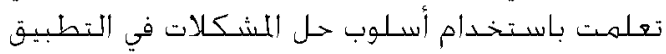

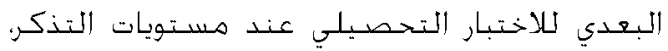

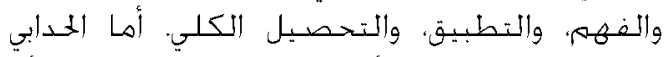

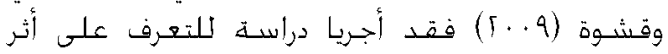

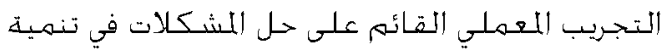

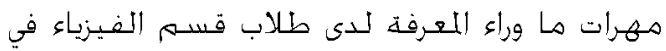

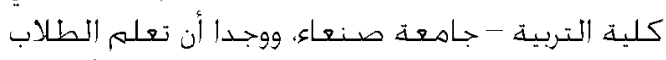

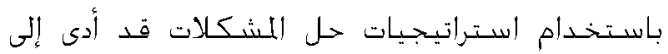

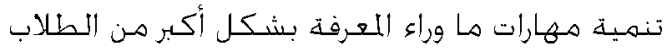

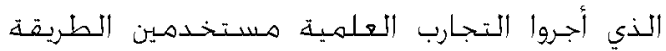

اللتقليدية.

ومن أهم أهداف التعلم المبني على المشكلة؛ تنمية

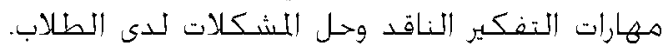

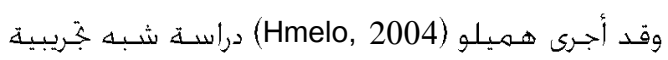

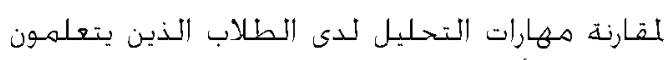

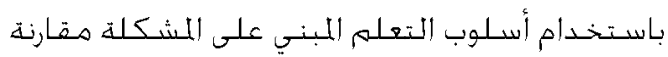

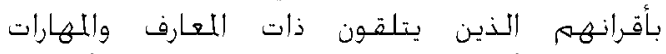

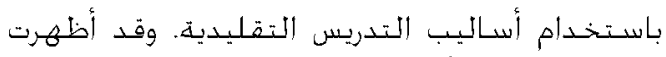

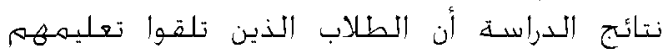

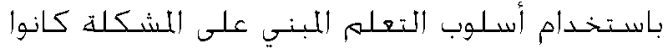

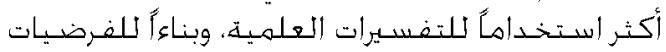


مشـكلة الدراسـة

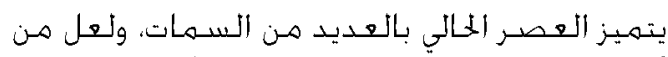

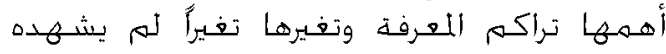

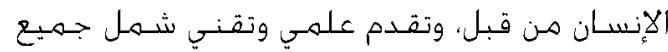

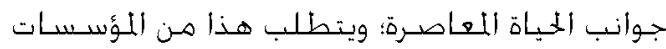

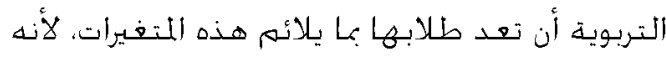

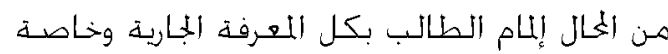

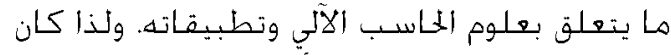

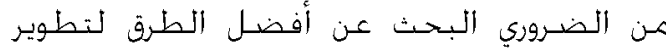

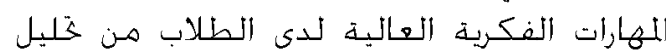

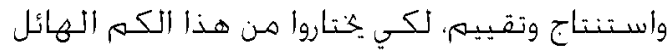

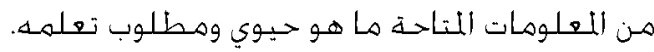
وكل هذا يلقي بالمسئولية على التربويين للبحث

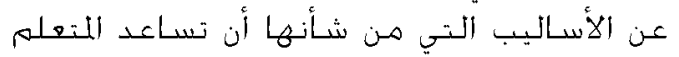

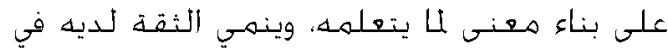

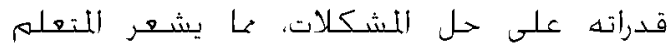

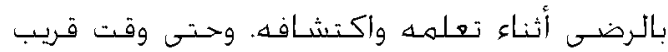

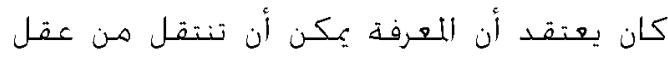

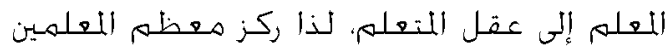

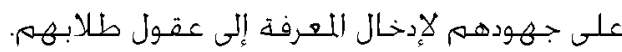

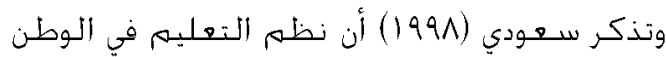

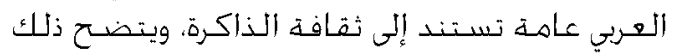

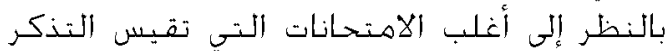

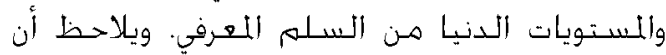

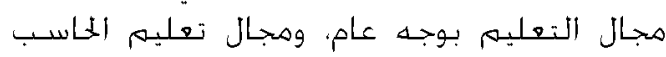

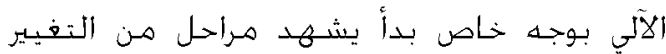

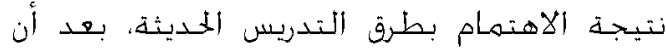

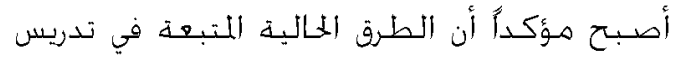

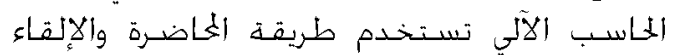

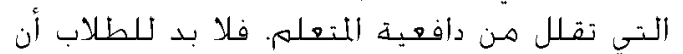

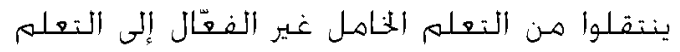

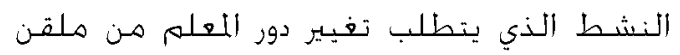

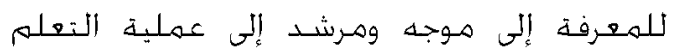

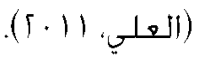

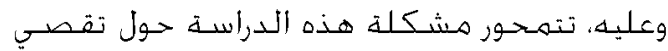

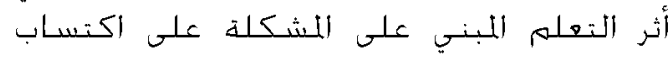

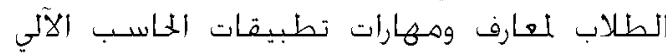

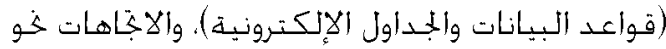

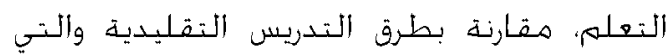
تعنمد على المعله بشكل رئيس.

أسئلة الدراسـة أجابت هذه الدراسـة عن الأسئلة التالية:
فد استفادت من الدراسـات السابقة من أجل بناء

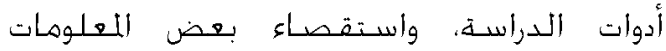

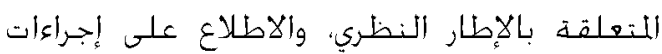

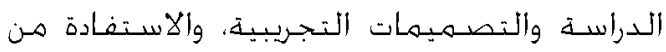
طريقة عرض بعض النتائج ومناقشتها. أهمية الدراسـة

Albanese \& Mitchell, ) وفقا ألبينس ومتشل

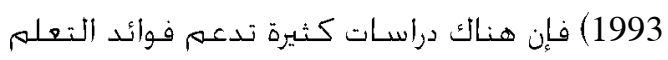

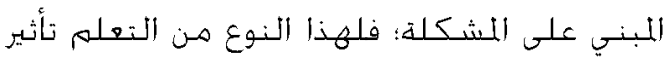

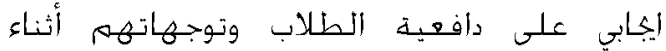

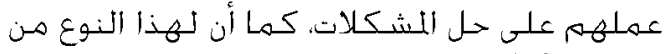

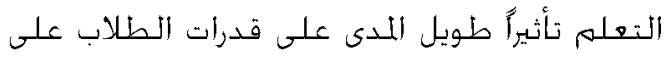

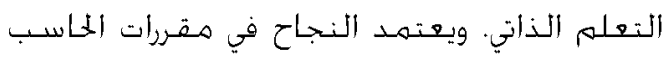

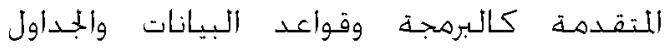

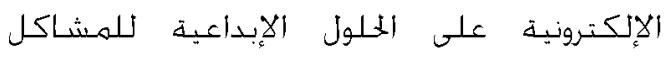

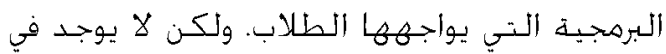
الأدبيات إلا القليل حول استخدام وتطبيق أسـلوب الساب

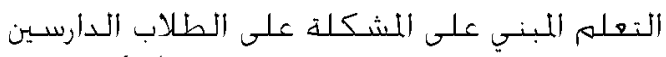

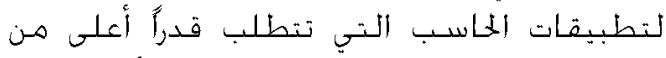
قدرات التفكير كبرمجه قواعد البيانات أو التهامل ألون مع الجداول الإلكترونية.

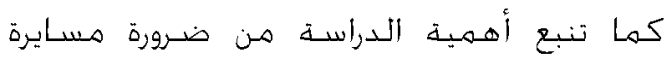

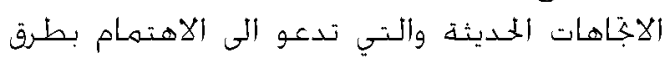

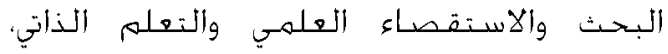

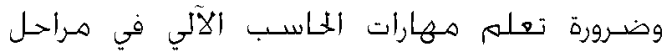

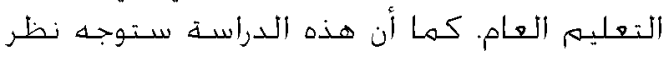

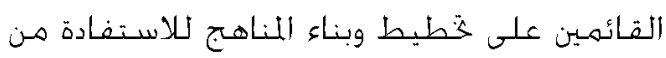

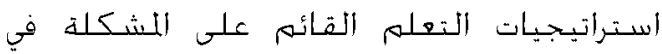

$$
\text { تدريس علوم الخاسـب الآلي. }
$$

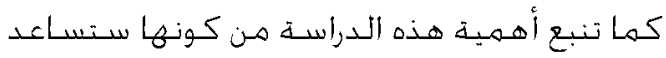

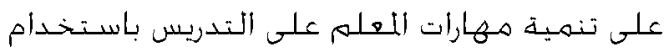

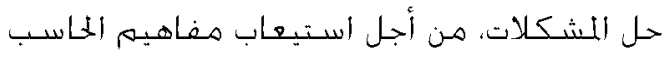

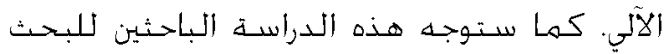

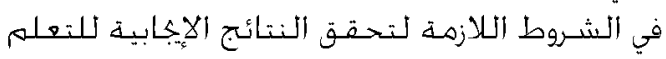

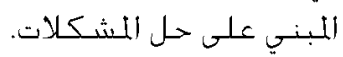

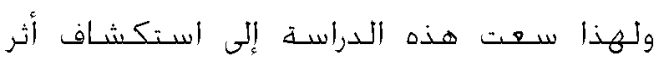

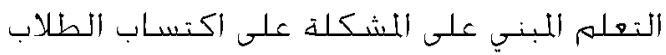

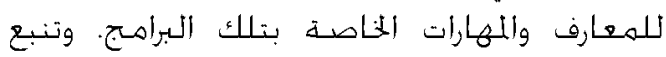
أهميذ هذه الدراسـة من الخاجذ إلى التعرف على الماتل

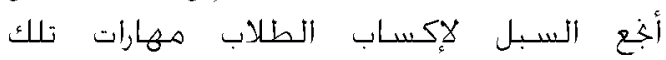

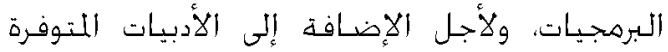

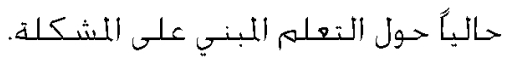


تتبح للمتعلم صنع فهم ذي معنى من خلال ربط

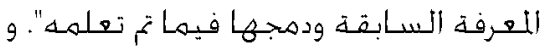

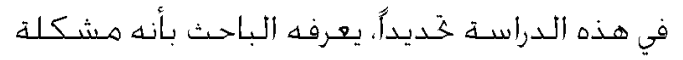

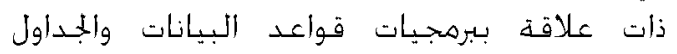
الإلكترونية. أسلوب التعلم التقليدي: هو أسـلوب التدريس الذئي

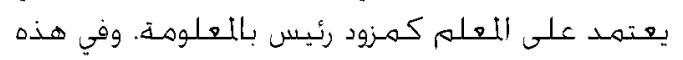

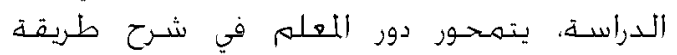

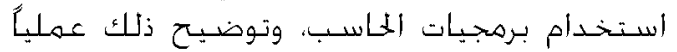
أمام الطلاب، ثم فيام الطلاب منفردين بإجراء الخطوات التي فام بها المعله.

فاعدة البيانات (Database) : هي هجهوعة من

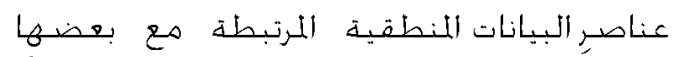

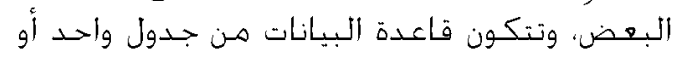
أكثر. ويتكون الجدول من سـجل (Record) أو أكثر

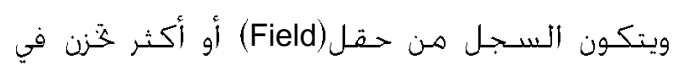

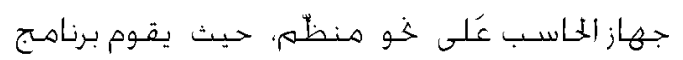

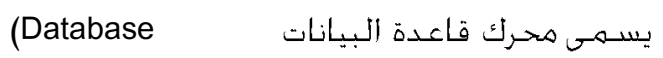
هichine)

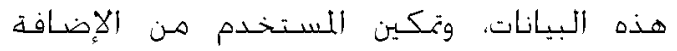

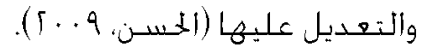

برنامج فاعدة البيانات (Database Application) :

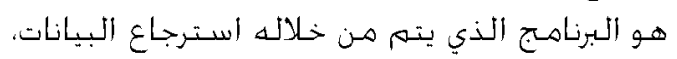

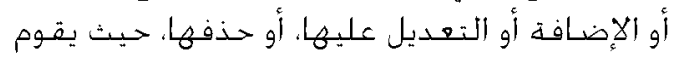

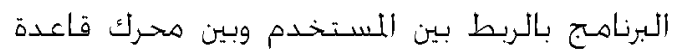
البيانات، لأداء تلك اللهمهذ. الجداول الإنكترونية (Spread Sheets)؛ هي براهـج حاسوبية نتكون من خلايا (Cells) ينم ادخال

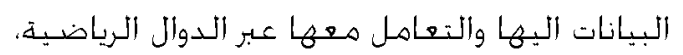

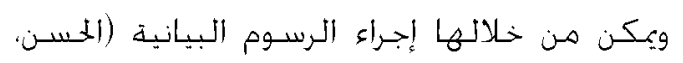

$$
.(1 \cdots 9
$$

\section{حدود الدراسة}

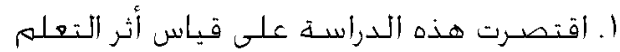

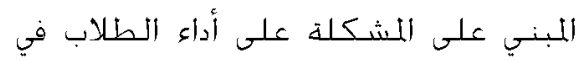

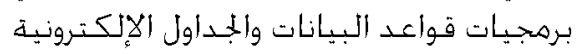

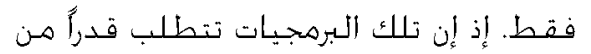

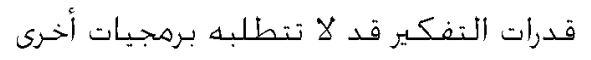

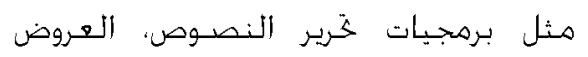
التقديمية، وبرمجيات الرسمى البسيطة.

أ. كما اقتصـرت هذه الدراسة على عينة من التهن

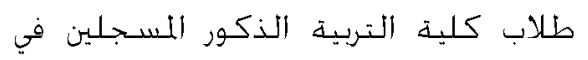

ا. ما أثر التعلم المبني على المشكلة على التهابل

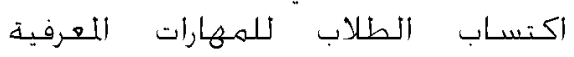

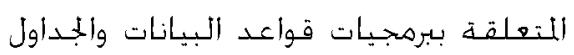
الإلكترونية مقارنة بأسلوب تدريس الحاسب الحاسب الآلي التقليدي؟

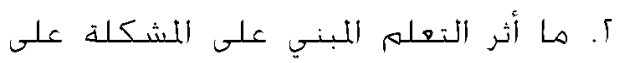

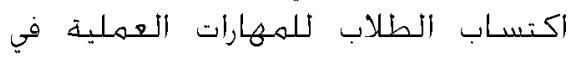

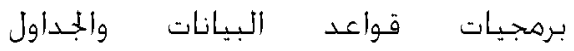

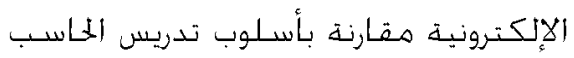

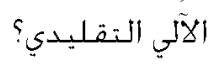

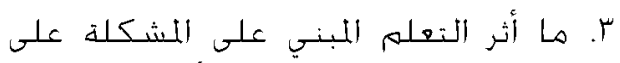

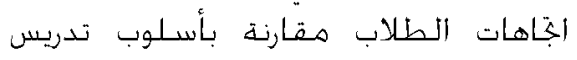

$$
\text { الحاسب الآلي التقليدي؟ مقارن }
$$

أهداف الدرأسة

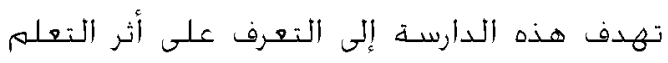

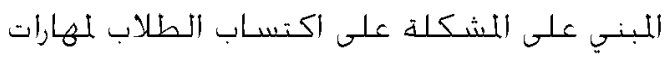

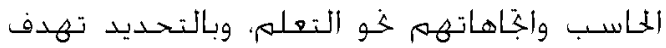

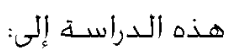

ا. التهرف على أثر التهله النبني على المشكلة التهائ

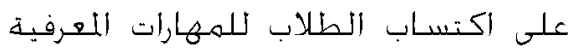

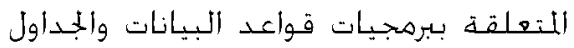

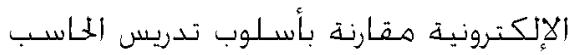

$$
\text { الآلي التقليدي. }
$$

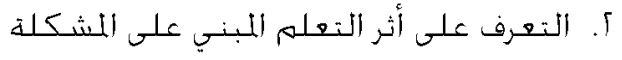

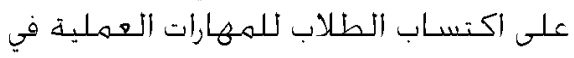

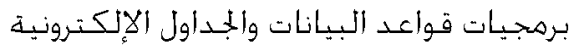

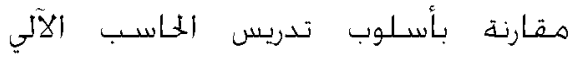

$$
\text { التقليدي. }
$$

با. التعرف على أثر التعلم المبنـي على المشكلة

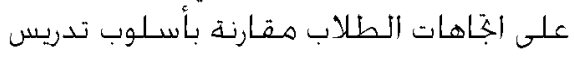

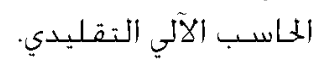

$$
\text { مصطلحات الدراسة }
$$

Problem-Based ( التعله المبني على المشكلة (Learning

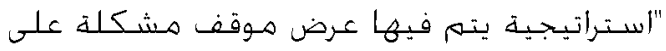

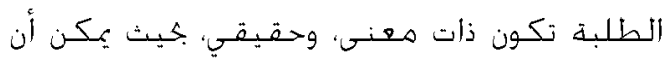

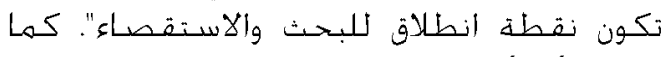

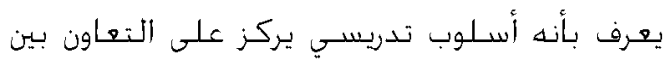

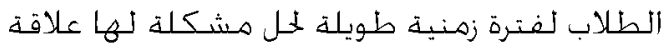

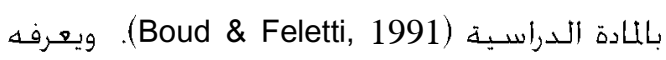

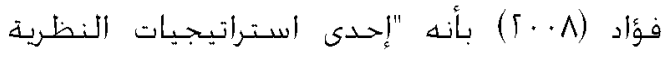

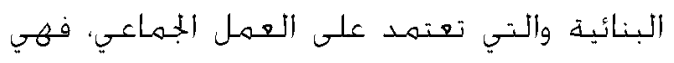


عينة الدراسـة

أجريت هذه الدراسـة على هجمـوعتين هـن الطبلاب،

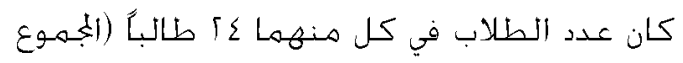

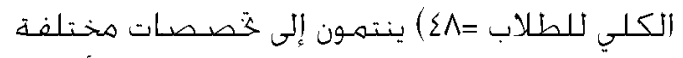

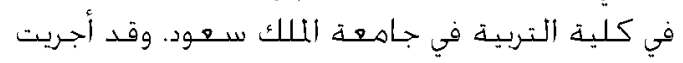

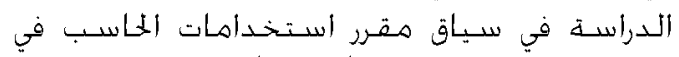

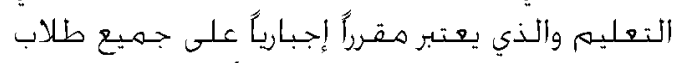
كلية التربية. وجّدر الإشـارة إلى أنه له لم يتهم توزيع

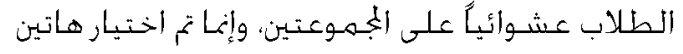

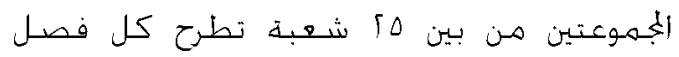

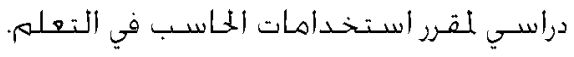

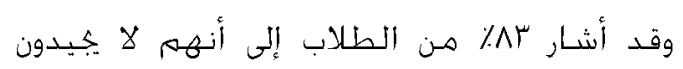

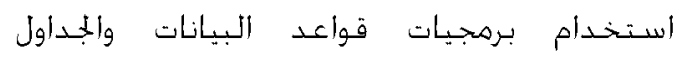

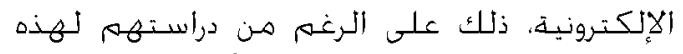

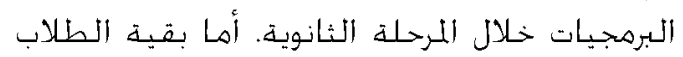

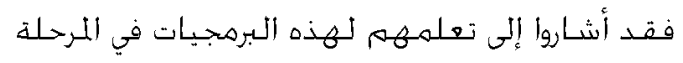

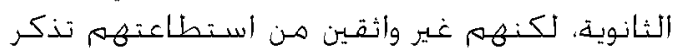

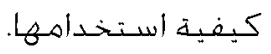

أدوات الدراسـة

تم في هذه الـدراسـ استخـدأم عدة أدوات للقياس

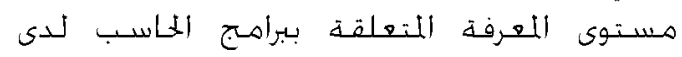

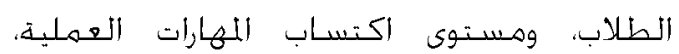

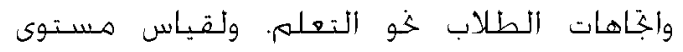

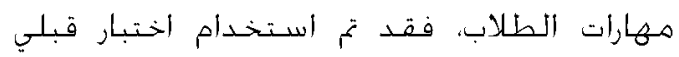

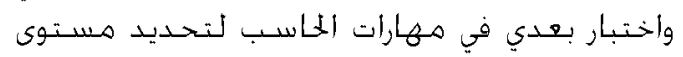

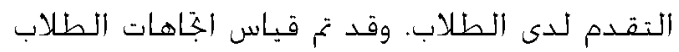

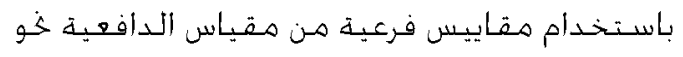

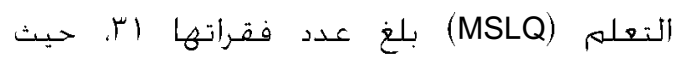

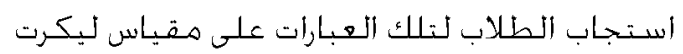

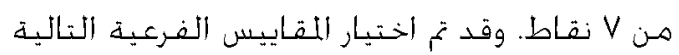

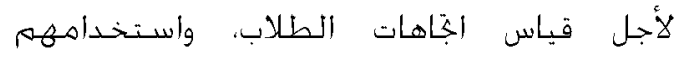

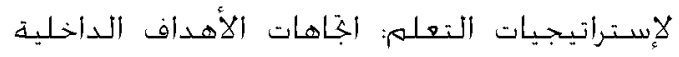

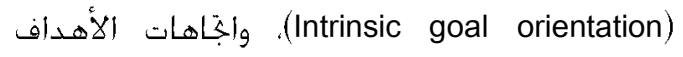
الخارجية (Extrinsic goal orientation)، وقيمد (لاهدات Self-) اللهمهذ (Task value)، والفاعلية الذاتية Pintrich, Smith, Garcia, McKeachin, ) (efficacy

$$
\text { 1993 a, b }
$$

- اختبار معارف تطبيقات قواعد البيانات

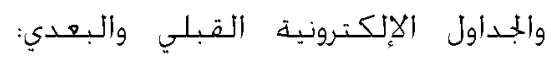

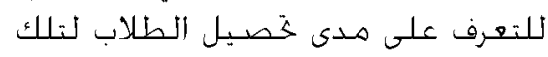

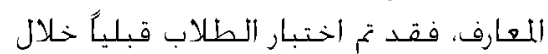

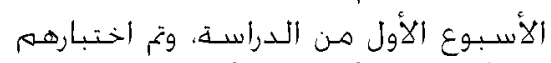

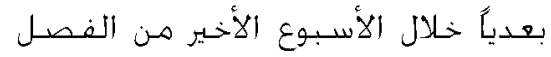

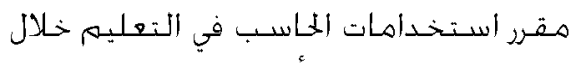

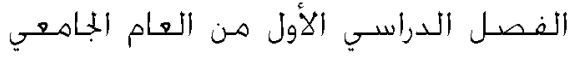
ه $\Sigma \Psi \mu / \mid \sum r T$

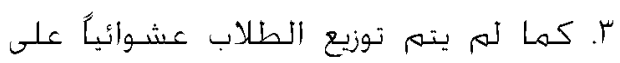
المجمهوعتين الضمابطة أو التجريبية، إذ تم إجراء

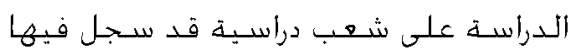

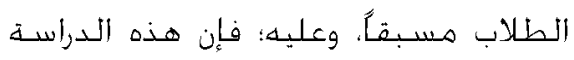

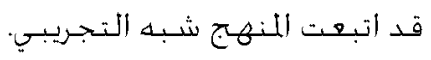

$$
\begin{aligned}
& \text { الطريقـة والإجـراءات }
\end{aligned}
$$

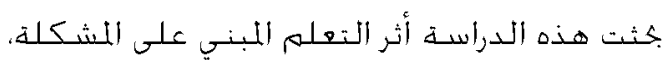

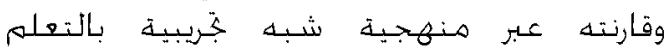

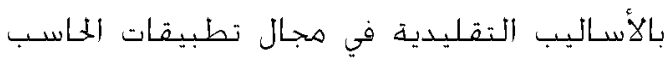
الآلي، وعلى وجـه التحـديد تطبيقات قواعد الاسي البيانات

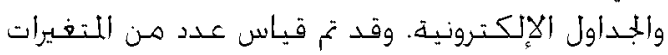

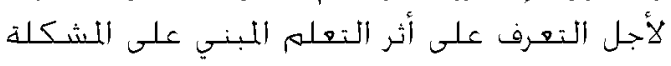

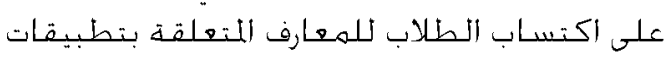
الخاسب، وعلى اكتساب مهارات الخاسب، والاجناهات

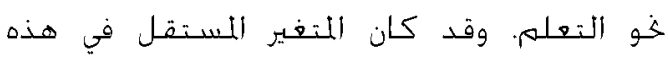

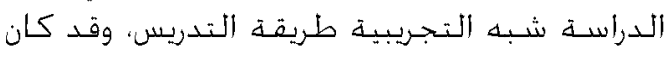

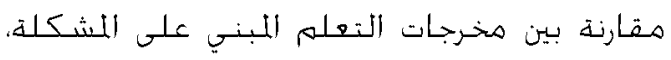

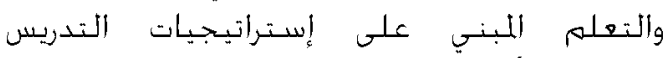

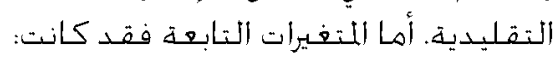

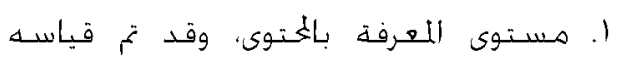

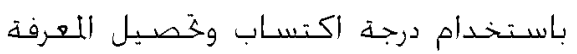
بين الاختبار القبـلي في المعلومات والاختبار وخديار

$$
\text { البعـدي. }
$$

I. مهارات استخدام تطبيقات الخاسب

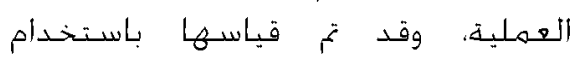

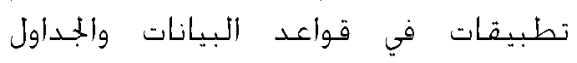

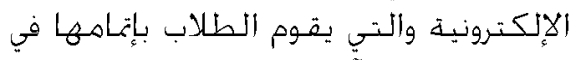

$$
\text { مختبر الخاسـب الآثي. }
$$

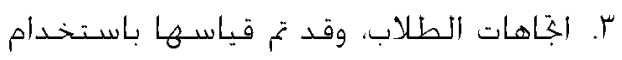
أداة MSLQ إسـتراتيجيات الدافهية للتهلم

Motivated Strategies for Learning )

(Questionnaire

وفيهما يتهلق بالمتهير المستقل (أسلوب التهلم) فقد

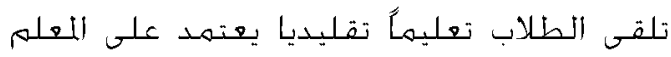

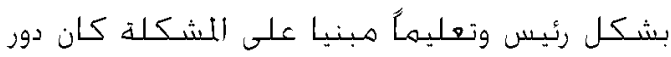

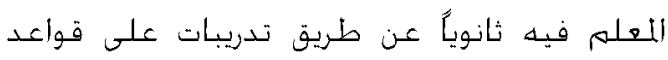

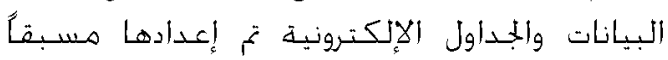

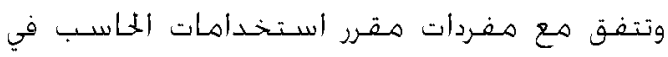
التهليهم الذي يتهم تدريســـ لـطلاب كلية التربية. 


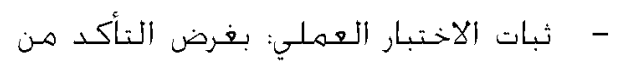

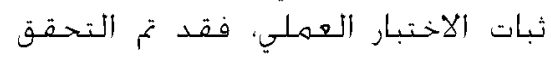

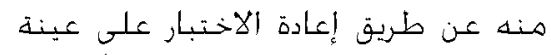

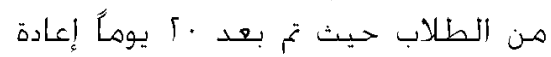

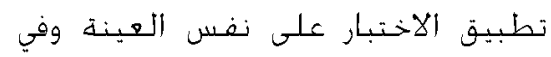

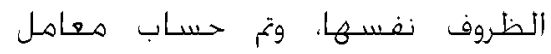

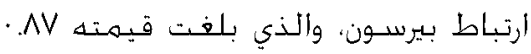

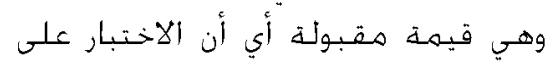
درجة مقبولة من الثبات.

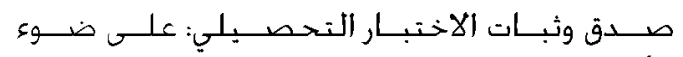

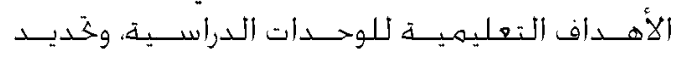

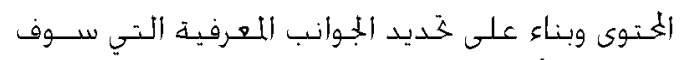

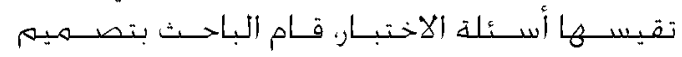

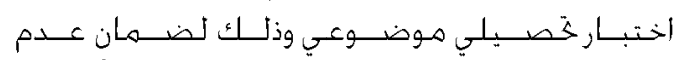
اختلاف اللصـحهين في تقـــير الإجبابـات عـن أسـائلة

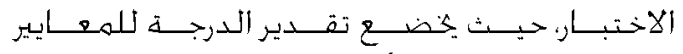

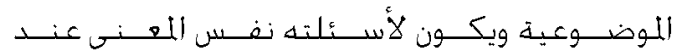

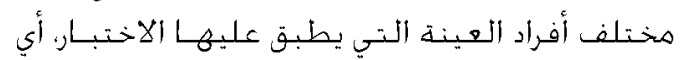
أن ألسؤال والإجـابة لا يقبلان ألتأويل.

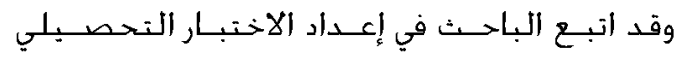
الخطوات التالية:

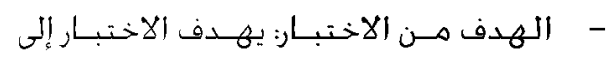

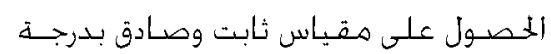

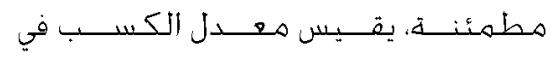

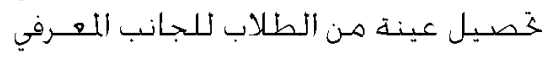

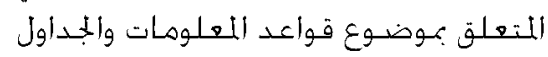
الإلكتـروني. - أبعاد الاختبار: التزم الباحت في خديد أبعاد

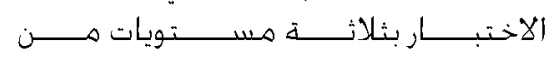

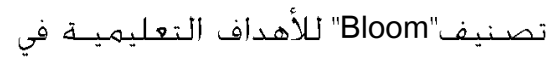

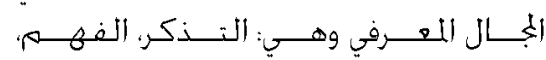

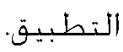

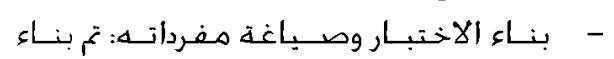

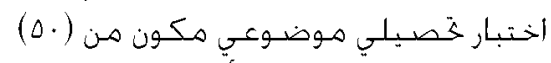

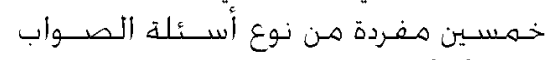

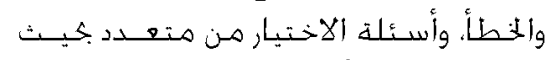

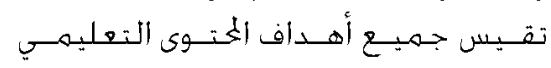
الذي تم اختباره.

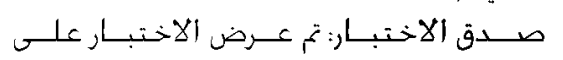

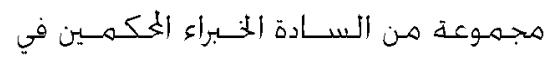

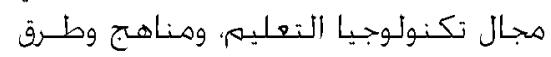

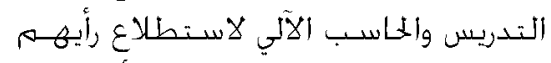

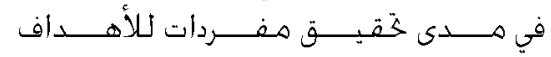

الدراسي. وفد تكون الاختبار من أسئلة نظرية حول برامج فون الاعد البيانات من الباتيات

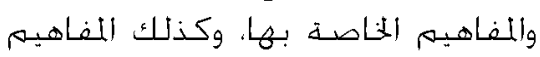
الخاصة ببرامج الجداول الإلكترونية. وقد تم الماهن

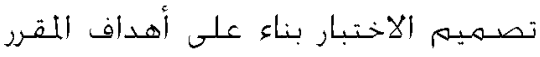

الدراسـي وذنك لضـمان صـدق الاختبار.

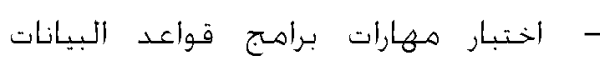

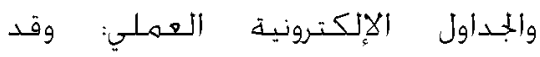

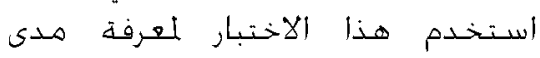

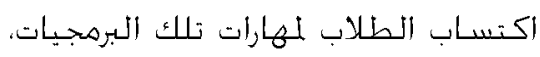

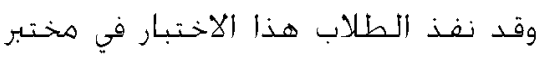

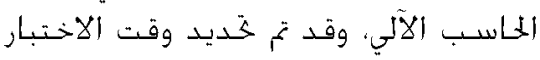

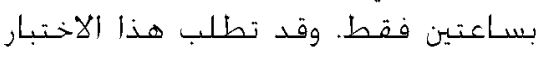

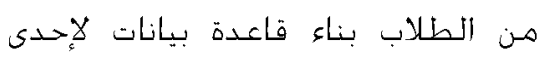

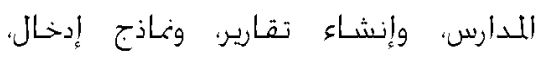

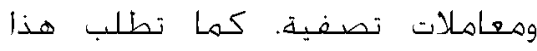
الاختبار من الطلاب إنشاء جدول كما إلكتروني

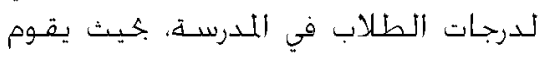

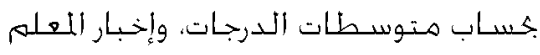

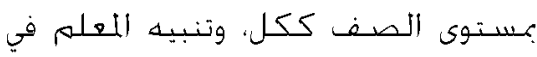

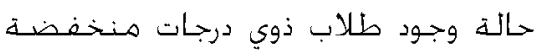
جداً.

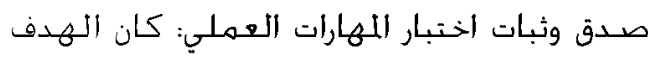

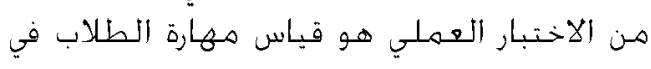

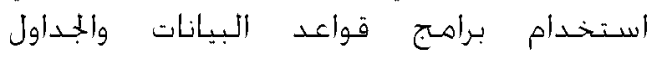

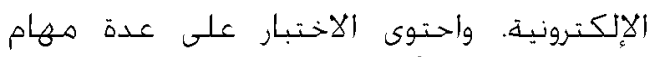

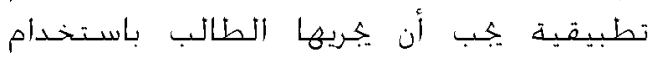
البرامج اللذكورة.

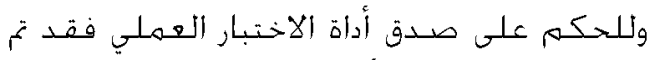

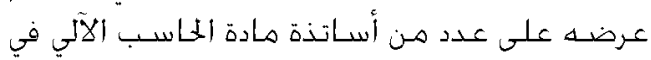

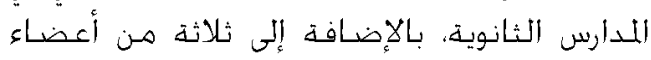

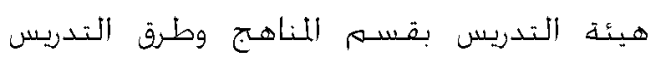

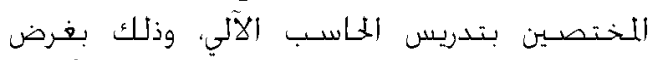

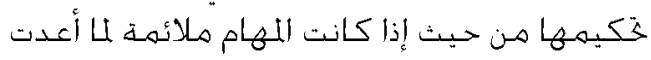

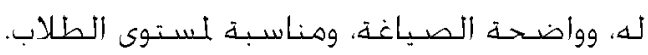

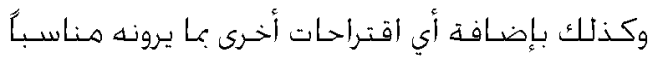

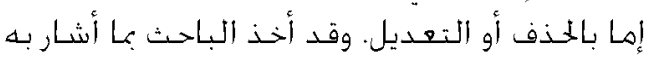

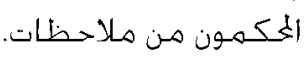

- - التجربة الاستطلاعية للاختبار العملي:

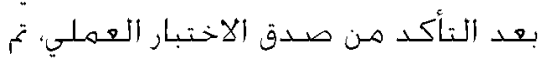

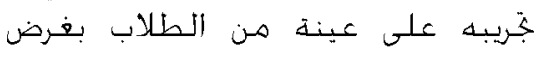

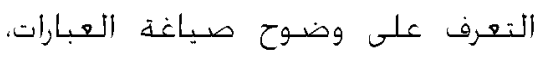

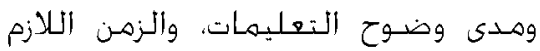

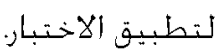


جدول المقان

معاملات الثبات لمقاييس الاتجاهات والدافعية

الفرعية التي استخدمت في الدراسة

\begin{tabular}{|c|c|c|}
\hline معامل ألفا & المقياس الفرعي & 5 \\
\hline$\cdot . v \leq$ & اتجاهات الأهداف الداخلية & 1 \\
\hline \multirow[t]{2}{*}{..$T r$} & اتجاهات الأهداف & r \\
\hline & الخارجية & \\
\hline .9 & قيمة المهمة & r \\
\hline \multirow[t]{2}{*}{. $.7 \Lambda$} & التحكم بالاعتقادات نحو & $\varepsilon$ \\
\hline & 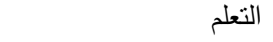 & \\
\hline. $.9 \Gamma$ & الفاعلية الذاتية & $\circ$ \\
\hline$\cdot . \wedge$ & قلق الاختبارات & 7 \\
\hline
\end{tabular}

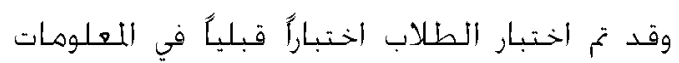

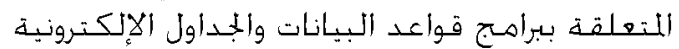

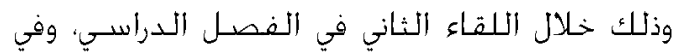

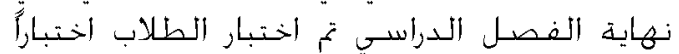

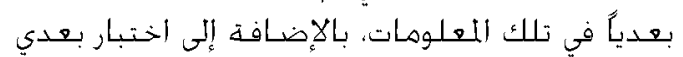

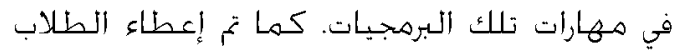

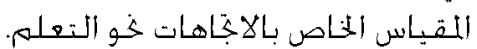

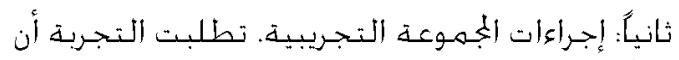

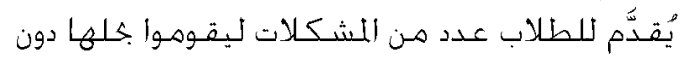

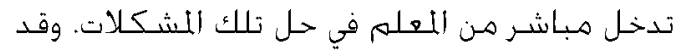

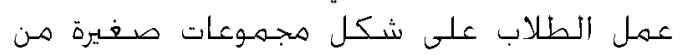

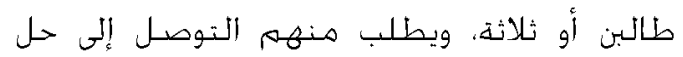

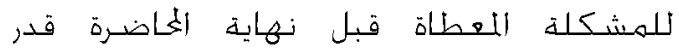

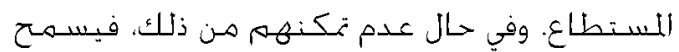

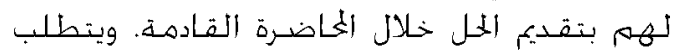

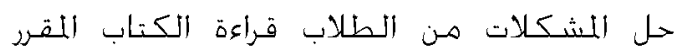

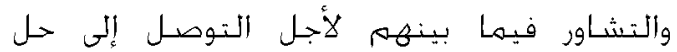

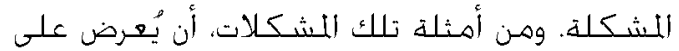

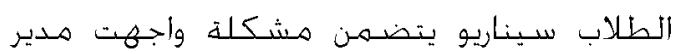

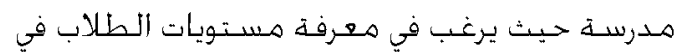

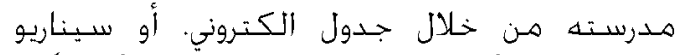
يتطلب من أمين مركز مصادر التهلم أن يُكَّون

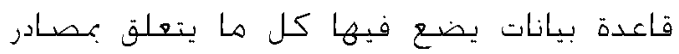

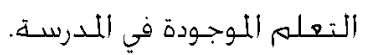

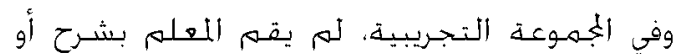

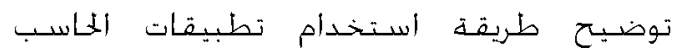

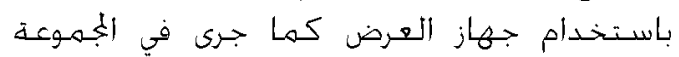

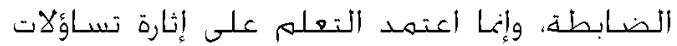

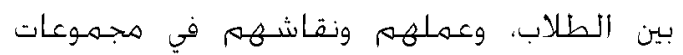

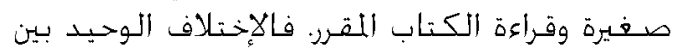

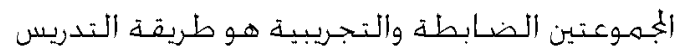
فقط. أما محتوى التعلم فقد كان متطابقاً بين التحرين المجموعتبن.

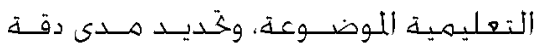

صياغة ووضوح كل سئوال.

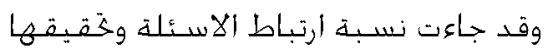

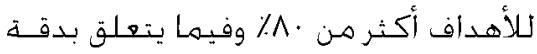

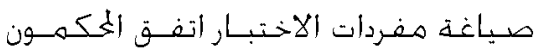

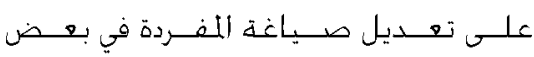

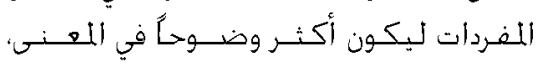

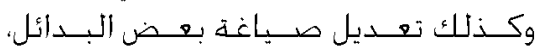
وفام الباحث بالتهديلات النلازهة.

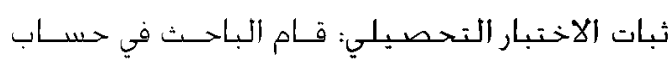

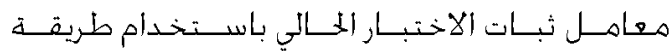

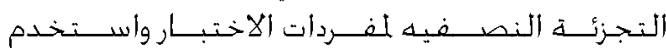

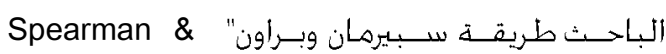
Brawn

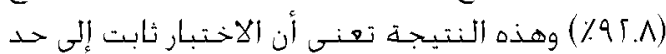

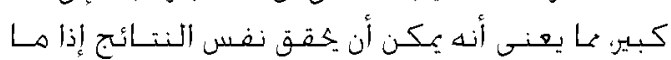

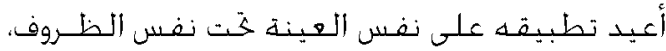

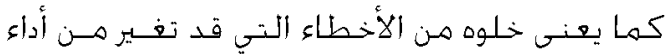
الفرد من وقت لآخر على نفس الاخط اللفردات.

مقباس إستراتيجيات الدافعية للتعلم (MSLQ): تم

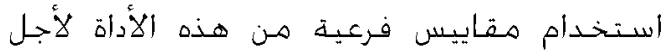

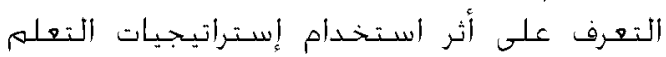

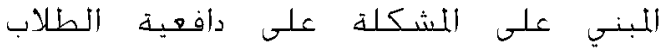

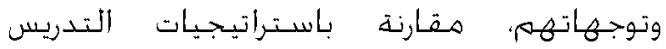

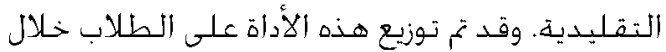

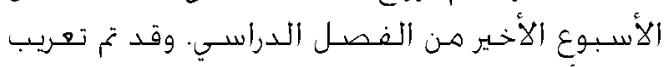

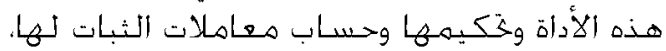
ويظهر جدول امعاملات الثبات لأجزاء اللقياس التيات التيات تم أستخدامها في هذه الدراسـة. إجراءات الدراسـة

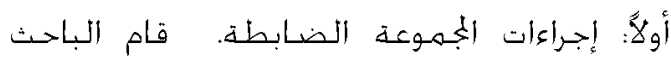
بتدريس الجُموعة الضـابطة لمدة سـاعتين أسبوعياً

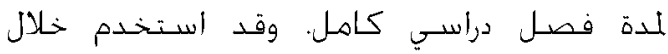

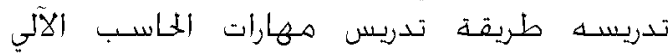

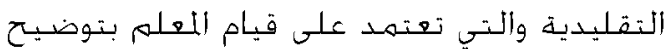

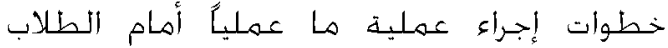

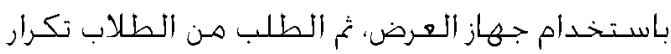

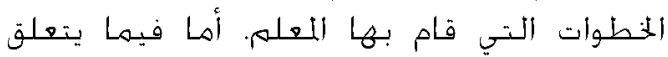

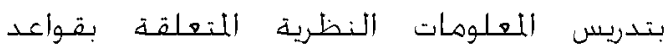
البيانات والجداول الإلكنترونبة، فقد فام المعلم بشرح

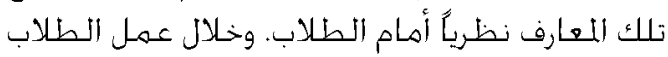

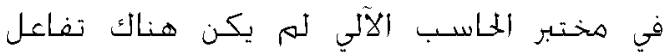

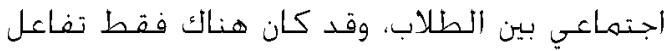
بين الطلاب والثعلم، أو الطالب وزميله الذي يماوره. 
الطلاب، والاسنهانة بالأسئلة لتوجيه عملية التهلهم.

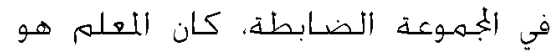

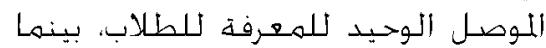

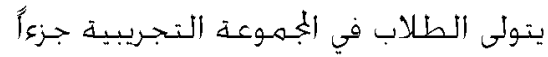

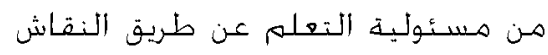

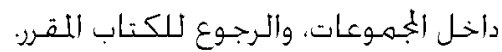

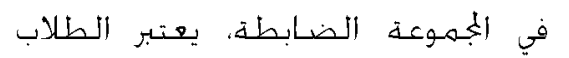

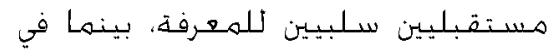

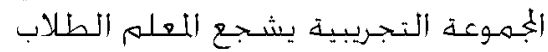
على أخاذ المبادرات، وطرح الأسئلة.

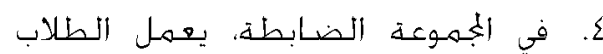

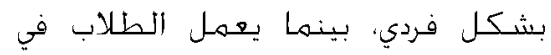

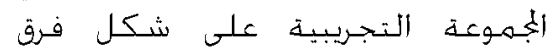

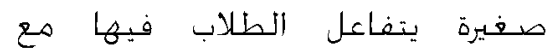

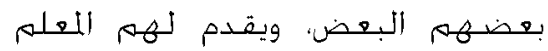
تغذية راجهة حول تقدمهيهم في اكنساب لهمه اللهارات. تعذات

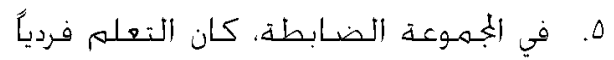

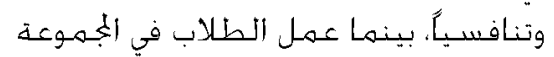

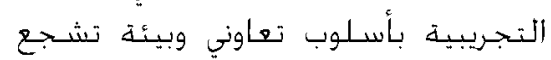
على المشاركية.

\section{النتائج}

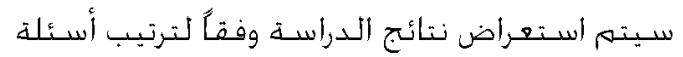

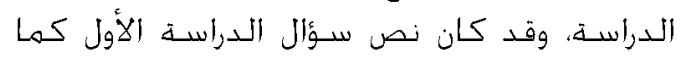

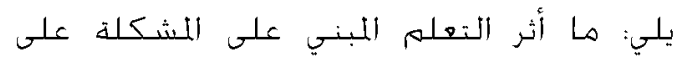

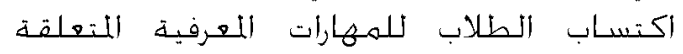

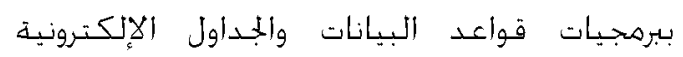

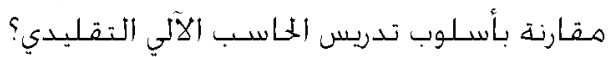
وقد تراوحت درجات الاختبار القبـلي في معارف برامه

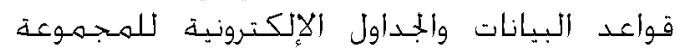

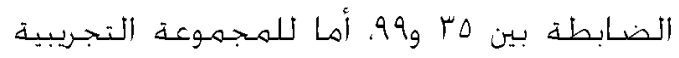

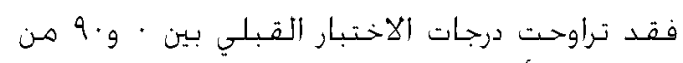

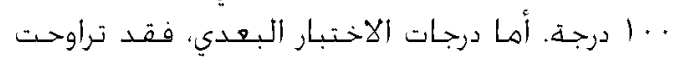

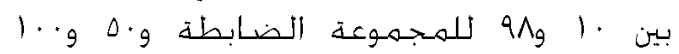

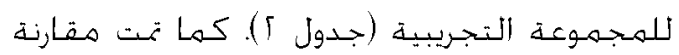

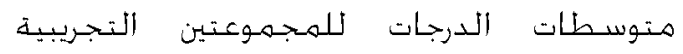
والضابطة. وقد أظهرت اللقارنة بين متوسطات التهات

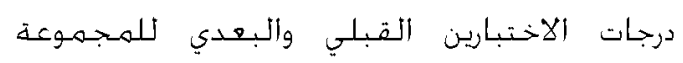

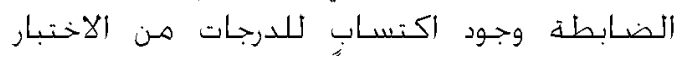

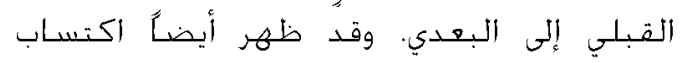

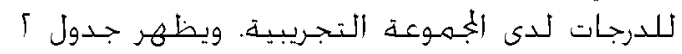

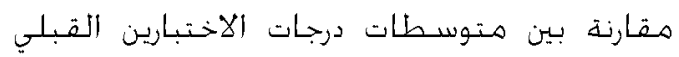

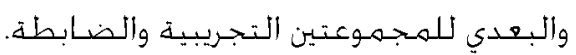

الفـروق في طريقة التدريس بين المجمهوعتين الضـابطة

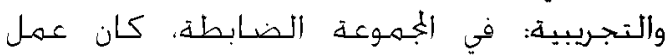

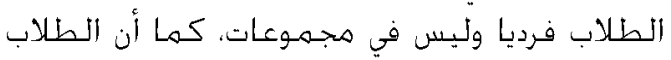

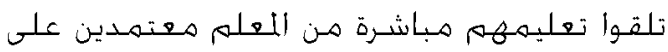

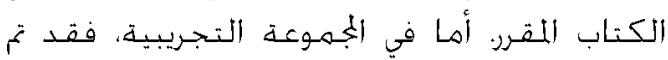

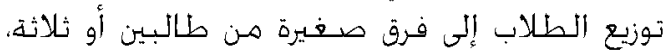

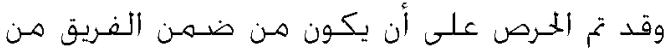

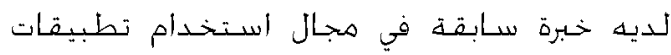

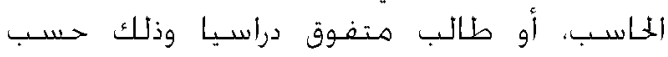

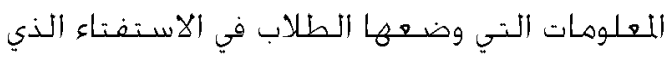
تلقوه في بـاية الفصي وهل الدراسي.

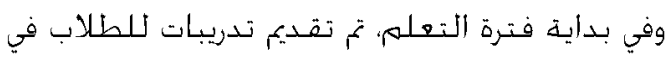

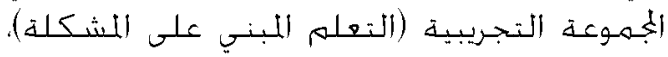

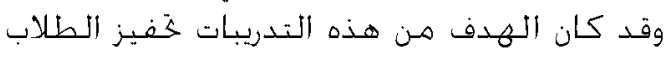

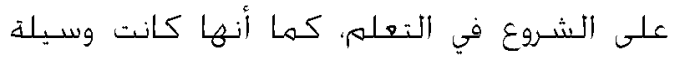

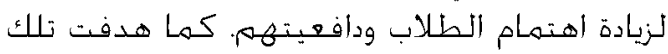

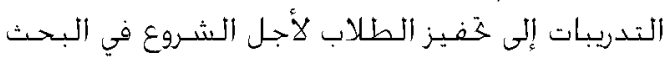

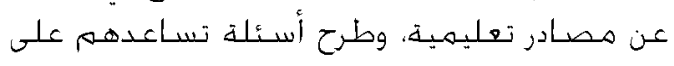

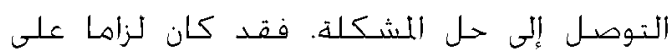

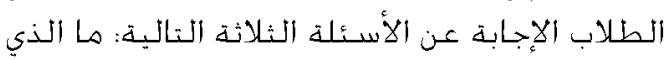

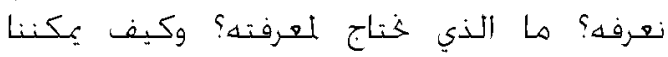

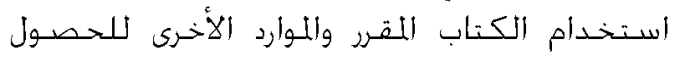

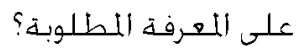

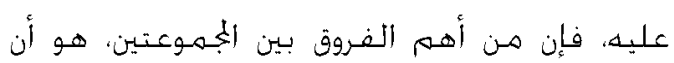

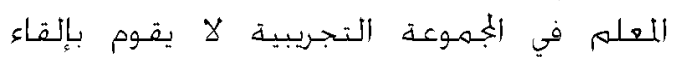

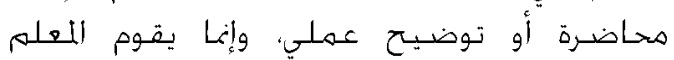

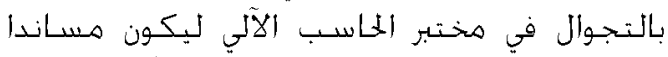

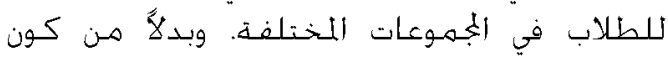

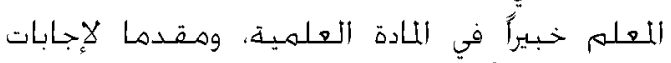

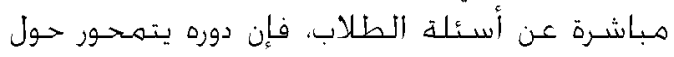

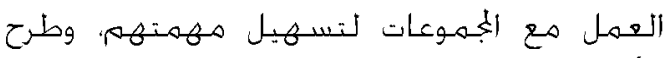

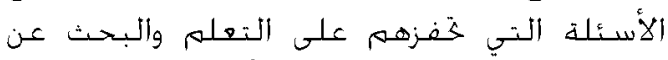

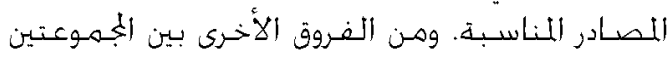

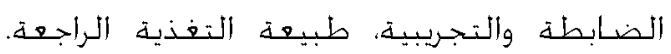

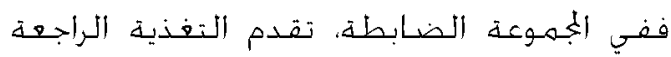

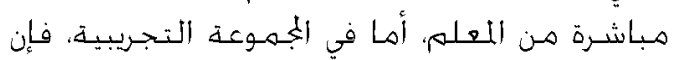
التغذية الراجهة تكـون متداولة بين الطياب.

ويمكن تلخيص الفـروقات بين المبمهوعة الضـابطة

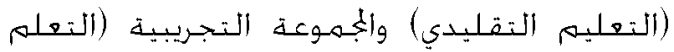

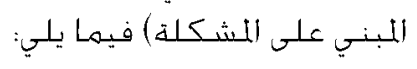

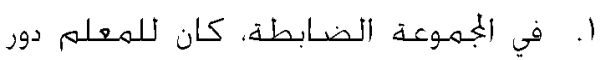

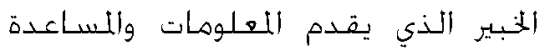

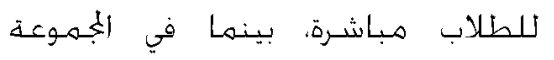

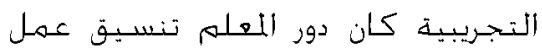


اللخبرات السيابقة في مجال المعارف المتهلقة ببرامج

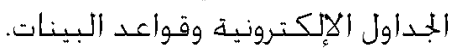

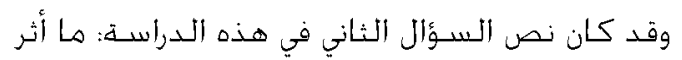

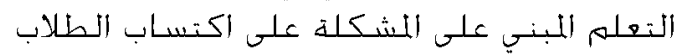
للمهارات العملية في برهجيات فواعد البهي البيانات

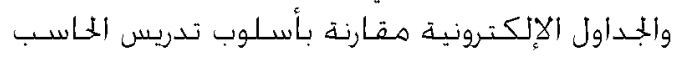

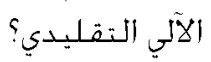

يعرض جدول ه المتوسطات والاخرافات الميارية

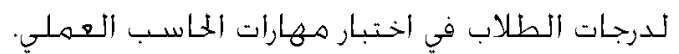

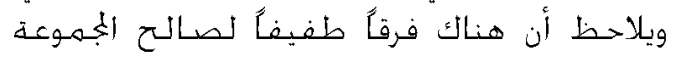

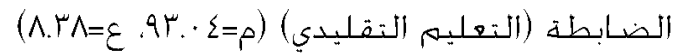

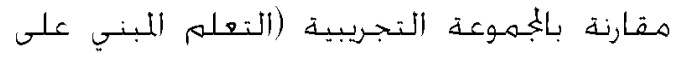

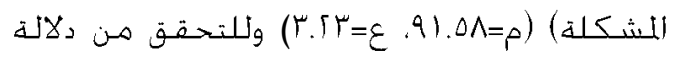

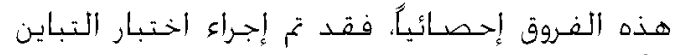

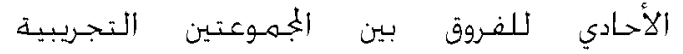
والضابطة.
وفد تمت مقارنة وخليل الدرجات التحهـيلية

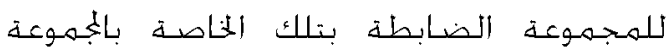

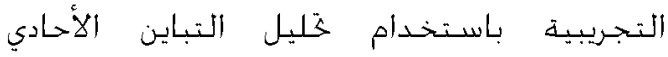
(ANOVA)

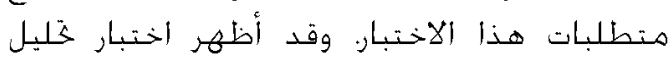

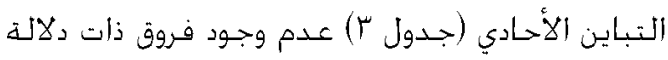

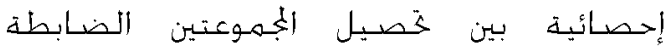

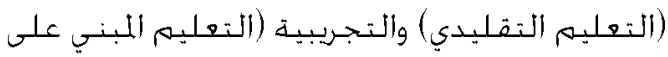

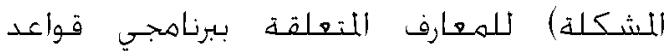

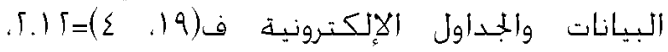

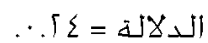

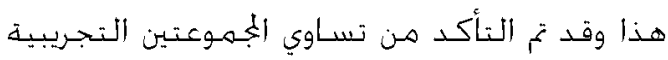

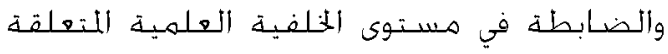

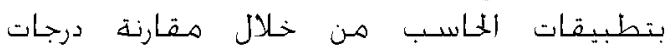

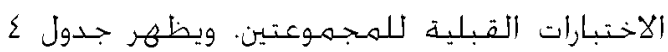

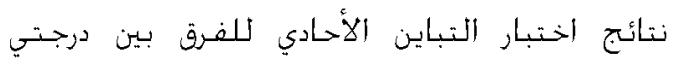

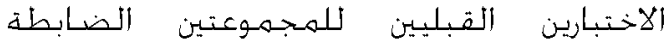

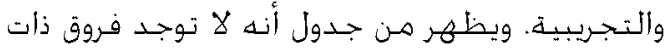

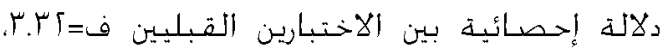

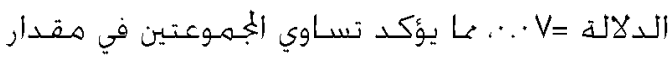

جدول

متوسطات الارجات التحصيلية القبلية والبعدية للمجموعتين الضابطة والتجريبية

\begin{tabular}{|c|c|c|c|c|c|c|}
\hline \multicolumn{2}{|c|}{ الانحراف المعياري } & \multicolumn{2}{|c|}{ المنتسط (الدرجة العليا= . 1) } & ن ن & \multicolumn{2}{|c|}{ الاختبار } \\
\hline \multicolumn{2}{|c|}{ tr.tr } & \multicolumn{2}{|l|}{01.90} & $r \varepsilon$ & \multicolumn{2}{|c|}{ الاختبار القبلي للمجموعة الضابطة } \\
\hline \multicolumn{2}{|c|}{10.17} & \multicolumn{2}{|l|}{$0 \wedge . \vee 0$} & $r \varepsilon$ & \multicolumn{2}{|c|}{ الاختبار البعدي للمجموعة الضابطة } \\
\hline \multicolumn{2}{|c|}{ Tr.t. } & \multicolumn{2}{|l|}{$\leqslant 0 . \cdot 1$} & $r \varepsilon$ & \multicolumn{2}{|c|}{ الاختبار القبلي للمجموعة التجريبية } \\
\hline \multicolumn{2}{|c|}{10.14} & $79 . \leqslant 0$ & & $r \varepsilon$ & \multicolumn{2}{|c|}{ الاختبار البعدي للمجموعة التجريبية } \\
\hline \multicolumn{7}{|c|}{ نتائج تحليل التباين الأحادي (ANOVA) للفروق بين المجموعتين التجريبية والضابطة في درجات التحصيل } \\
\hline 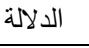 & ق قيمة ف & متوسط المربعات & 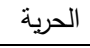 & & مجموع المربعات & المصدر \\
\hline$\cdot . r \varepsilon$ & t.IT & $\begin{array}{l}\text { rAq.VA } \\
\text { INt.rT }\end{array}$ & 1 & & $\begin{array}{l}V \varepsilon \cdot 7 . \cdots \\
V Y q . r T\end{array}$ & بين المجموعات المجموعات \\
\hline \multicolumn{7}{|c|}{ 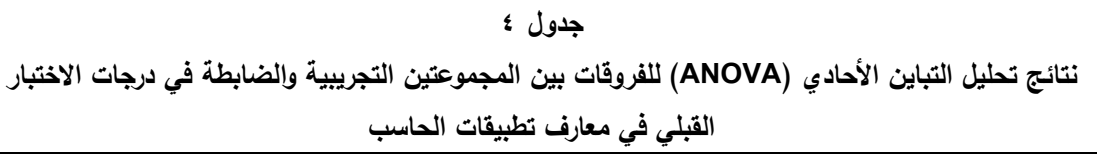 } \\
\hline 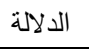 & قيمة ف & متوسط المربعات & 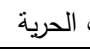 & & مجموع المربعات & المصدر \\
\hline$\because \cdot V$ & r.tr & 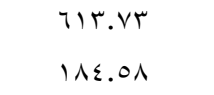 & 1 & & $\begin{array}{l}1 . \leqslant T 1 . \wedge r \\
11 \cdot V .0 .\end{array}$ & 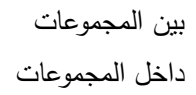 \\
\hline
\end{tabular}




\section{- جدول}

مقارنة متوسطات الدرجات في الاختبار العملي لمهارات الحاسب للمجموعتين الضابطة والتجريبية

\begin{tabular}{|c|c|c|c|}
\hline الانحراف المعياري & المنوسط (الدرجة العليا= . ) & ن & الاختبار \\
\hline A.rی & qт.. . & $r \leq$ & اختبار المهارات للمجموعة الضابطة \\
\hline שtr & 91.01 & $r \leq$ & اختبار المهارات للمجموعة التجريبية \\
\hline
\end{tabular}

Task )، وفيمد اللمهمدة (Extrinsic Goal Orientation) Value

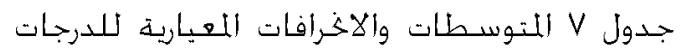

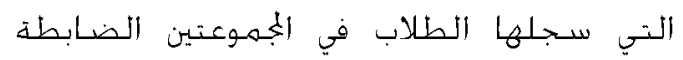

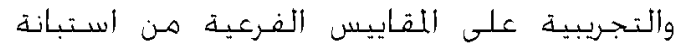

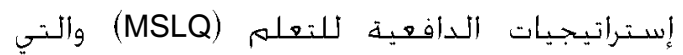

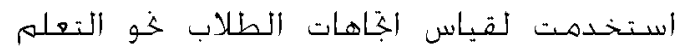

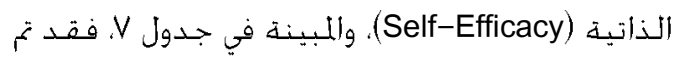

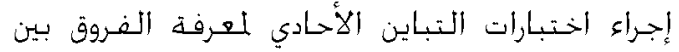

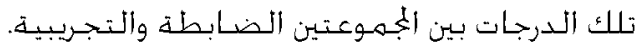
إنجاه الأهداف الداخلية: يظهر جدول V. درجات

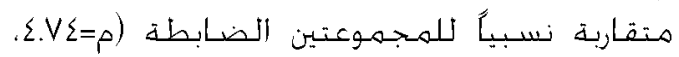

ويتضح هن جدول 1 أنه لا توجد فروق ذات دلالة النه

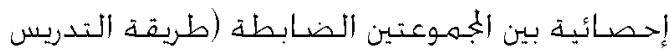

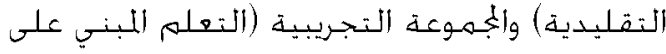

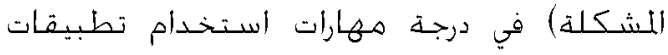

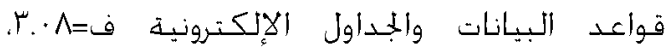
الدلالذ =

وقـد كان نص السـؤال الثالث في هذه الـدراسـة: ها

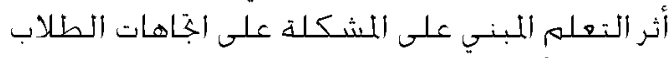

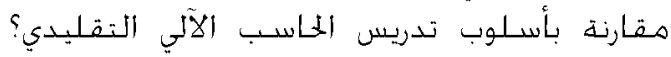

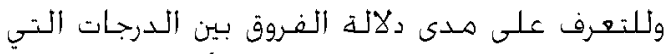

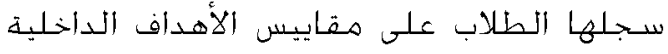
Intrinsic Goal Orientation)

جدول 1

نتائج تحليل التباين الأحادي (ANOVA) للفروق بين المجموعتين التجريبية والضابطة في درجات اختبار مهارات تطبيقات الجداول الإكترونية وقواعد البيانات

\begin{tabular}{|c|c|c|c|c|c|}
\hline الدلالة الد & قيمة ف & متوسط المربعات & درجات الحرية & المربعات & المصدر \\
\hline \multirow{2}{*}{. .10} & \multirow{2}{*}{$r . . \wedge$} & $\varepsilon \wedge \vee . \wedge \varepsilon$ & 19 & A.rE.rY & بين المجموعات \\
\hline & & $191 . \wedge \varepsilon$ & $\varepsilon$ & Vor.ro & داخل المجموعات \\
\hline
\end{tabular}

ج جدول va

المتوسطات والانحرافات المعيارية للمقاييس الفرعية من استبانة MSLQ لقياس اتجاهات الطلاب نحو التطلم

\begin{tabular}{|c|c|c|c|}
\hline الانحراف المعياري & المتوسط & 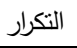 & المقياس الفرعي \\
\hline & & & اتجاهات الأهداف الداخلية \\
\hline $1 . \leqslant 9$ & $\varepsilon . V \leq$ & $r \leq$ & المجموعة الضابطة \\
\hline \multirow{2}{*}{1.09} & $\varepsilon .9 V$ & $r \leq$ & المجموعة التجريبية \\
\hline & & & اتجاهات الأهداف الخارجية \\
\hline $1 . \wedge 7$ & $\varepsilon . \wedge 7$ & $r \leq$ & المجموعة الضابطة \\
\hline \multirow[t]{2}{*}{1.70} & $\varepsilon .94$ & $r \leq$ & المجموعة التجريبية \\
\hline & & & قيمة المهمة \\
\hline 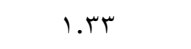 & $0 . r \leq$ & $r \leq$ & المجموعة الضابطة \\
\hline \multirow[t]{2}{*}{1.01} & 0.19 & $r \leq$ & المجموعة التجريبية \\
\hline & & & الفاعلية الذاتية \\
\hline I.rT & $0.7 \leq$ & $r \leq$ & المجموعة الضابطة \\
\hline \multirow[t]{2}{*}{1.49} & $0 . r 4$ & $r \leq$ & المجموعة التجريبية \\
\hline & & & المنتوسط الكلي للمقاييس \\
\hline 1.71 & 0.99 & $r \leq$ & المجموعة الضابطة \\
\hline 1.70 & $\varepsilon .9 V$ & $r \leq$ & المجموعة التجريبية \\
\hline
\end{tabular}




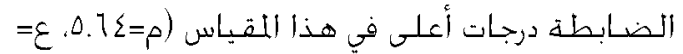

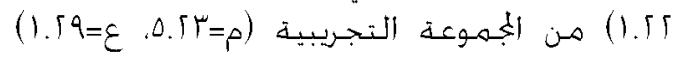

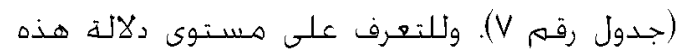

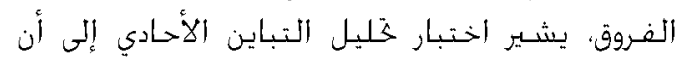

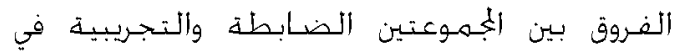

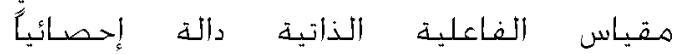
ف

ملخص نتائج مقياس MSLQ: بظهر جدول رقهم V.

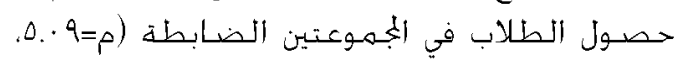

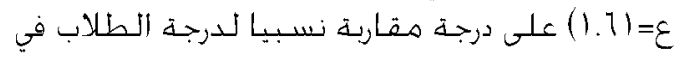

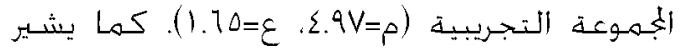

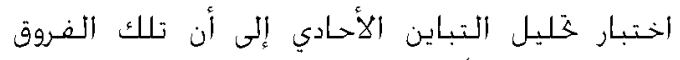

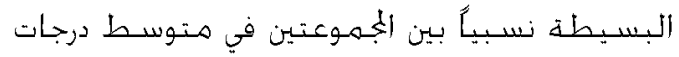

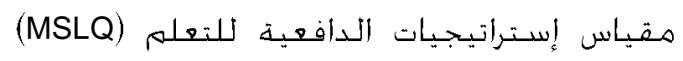

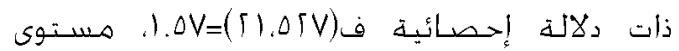
$\therefore \Delta=\Delta{ }^{\prime}$

وبوجه عام، نشير نتائج خليل بيانات اللقاييس

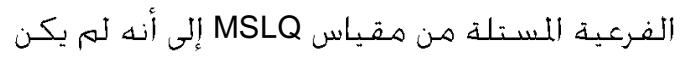

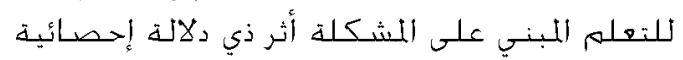
على الجاهات الطلاب خو التعله.

\section{مناقشَهـ النتائج}

تمحسور سـؤال الدراسـة الأول حول أثر التهلم المبني

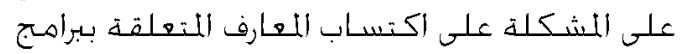

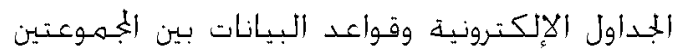

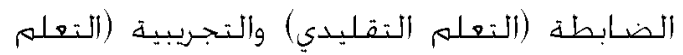

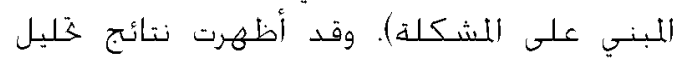
التبابن الأحادي عدم وجود فروف ذات دلالة إحسائية

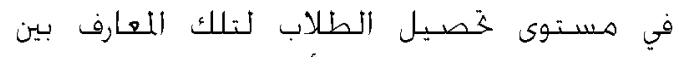

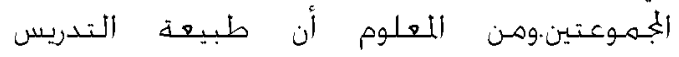

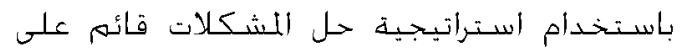

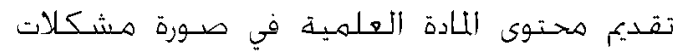

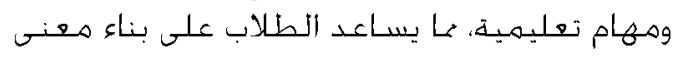

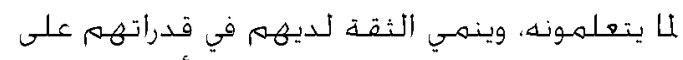

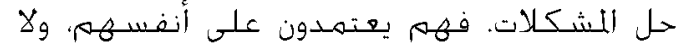

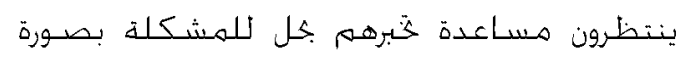

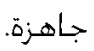

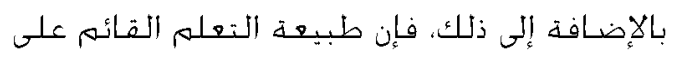

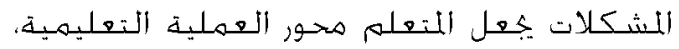

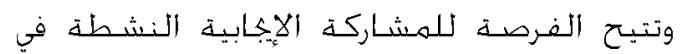

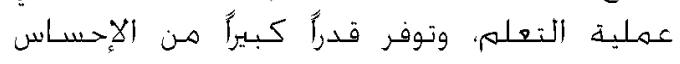

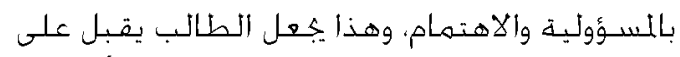

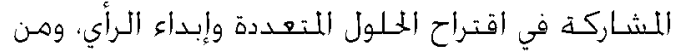

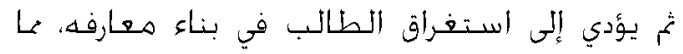

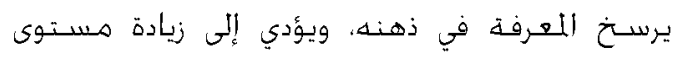

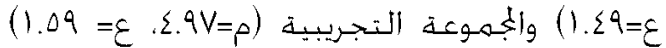

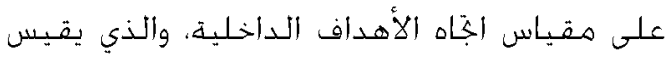

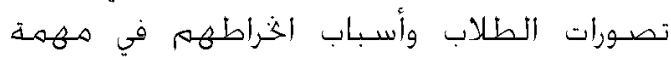

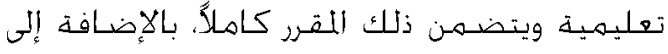

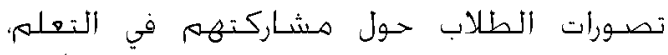

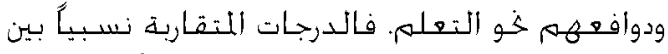

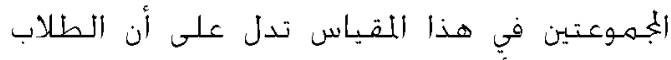

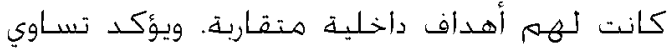

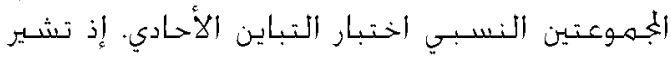

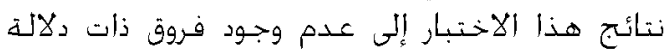

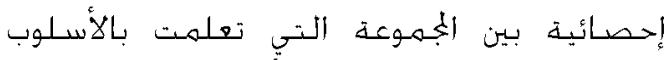

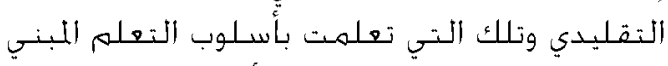

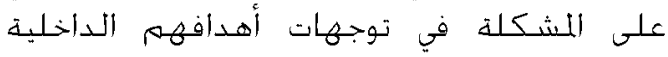

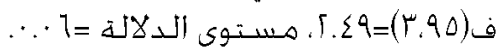

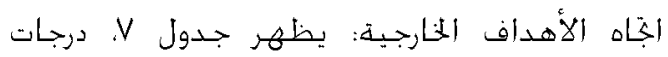

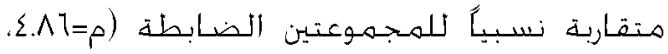

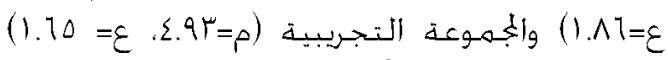

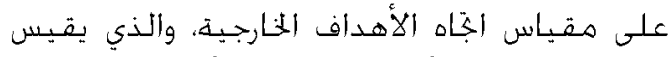

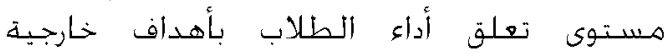

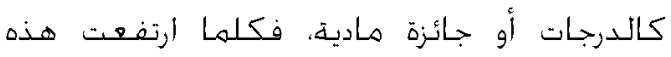

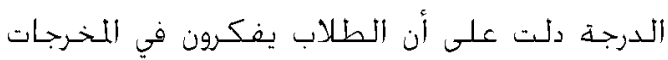

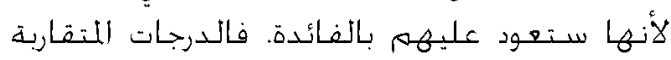

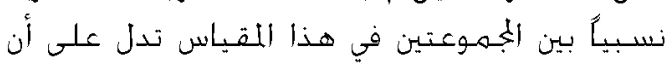

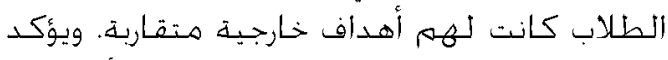

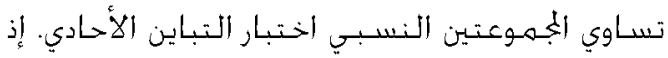

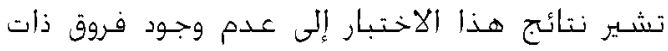

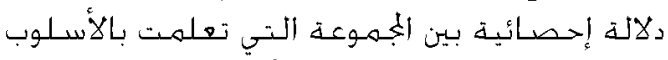

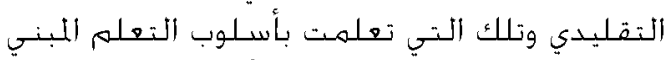

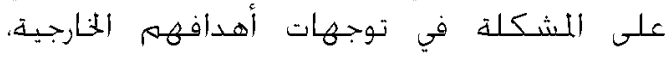

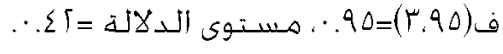

مقياس قيمة المهمة: ويقيس هذا المقياس مدى

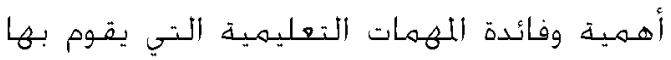

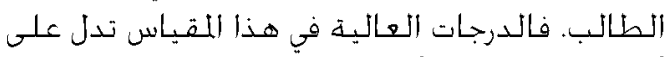

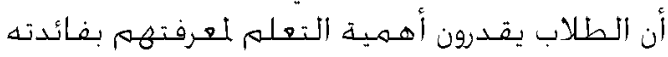

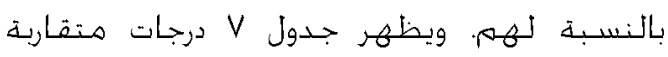

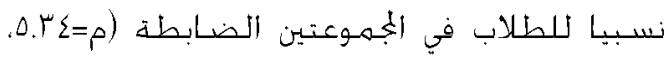

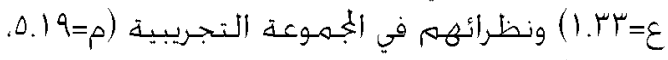

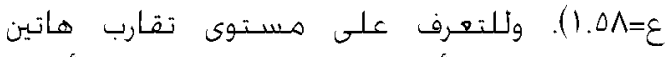

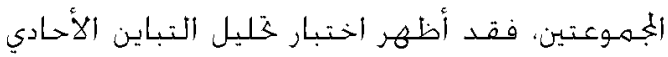

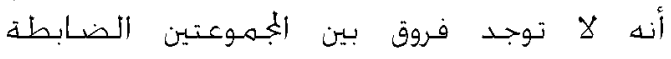

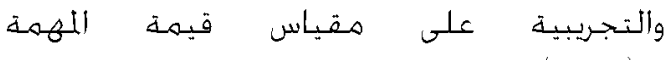
فـ( )

مقياس الفاعلية الذاتئ: ويقبس هذا المقياس مستوى ثقدة الطلاب في قدراتهم على أداء وإتقان

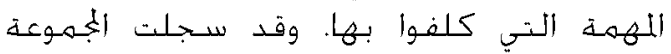


ودار سؤال الدراسـة الثاني حول أثر التعلم اللبني

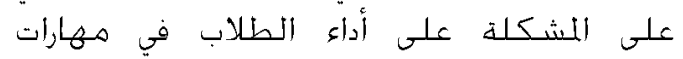

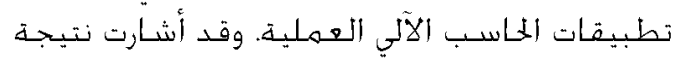

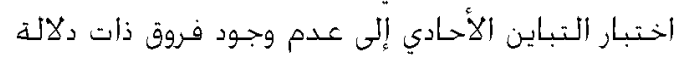

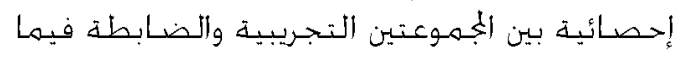

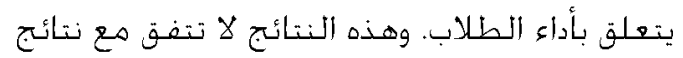

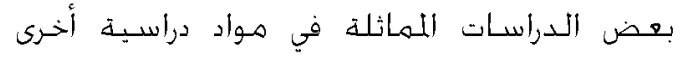

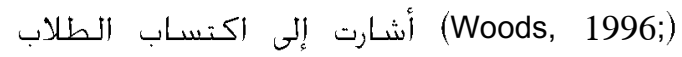

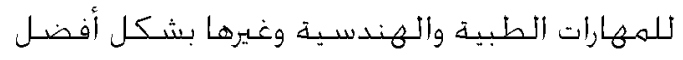

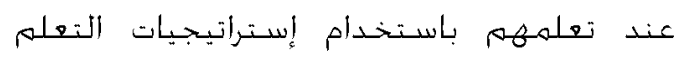

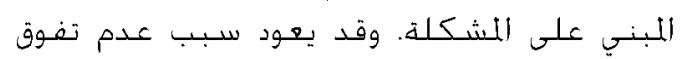

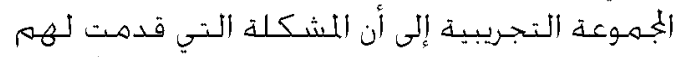

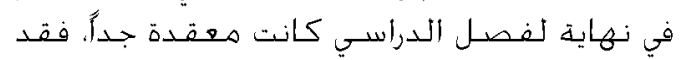

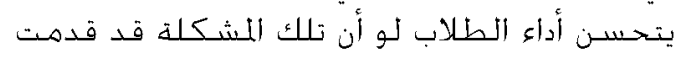

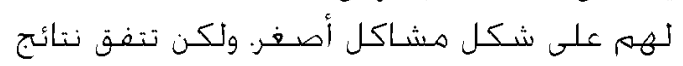

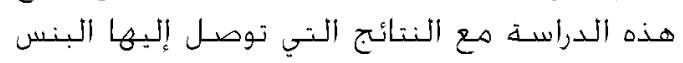

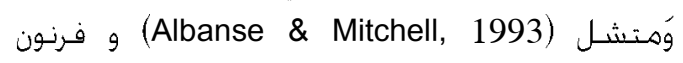
وَبليك (Vernon \& Blake, 1993) وَدوتشي وآخحرون والتي أشـارت إلى أن التهله (Dochy et al., 2003)

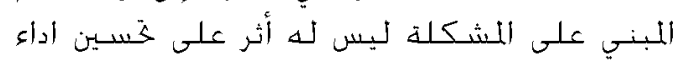

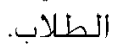

وأخيراً، تمحسور سـؤال الدرأسـة الثالث حول أثر التهله

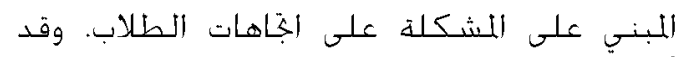

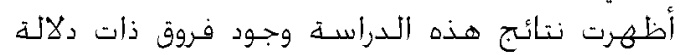

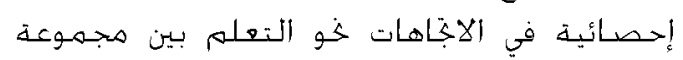

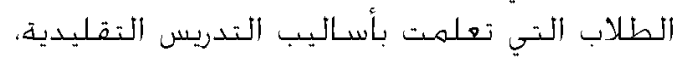

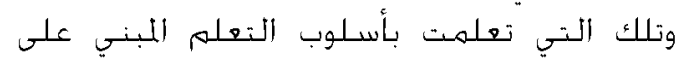

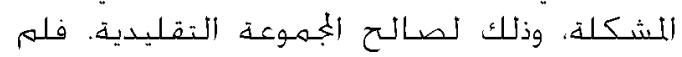
بكن للتعلم المبني على المشكلة أثر ايكابي على المعابه

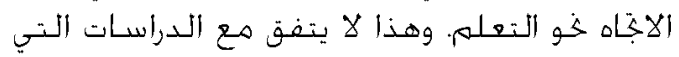

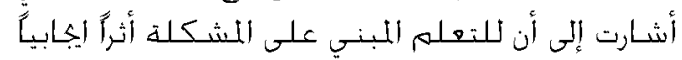

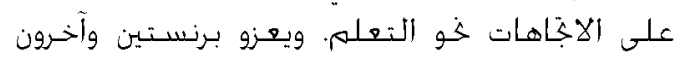

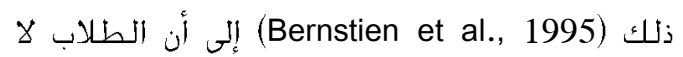

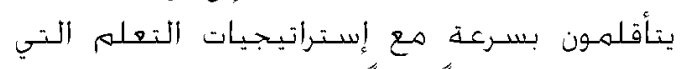

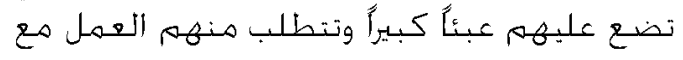

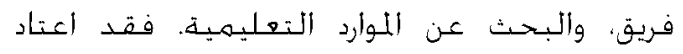

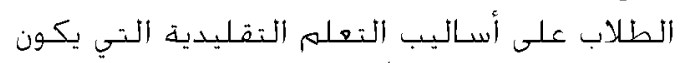
دور الطالب فيها سلبيً. التوصيات

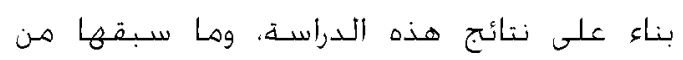

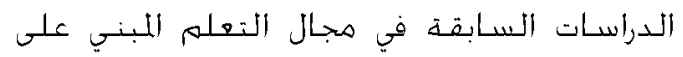
المشكلة، فإن هذه الدراسـة توصي في بـا يلي:
التحصيل، وذلك على نقيض الطريقة التقليدية

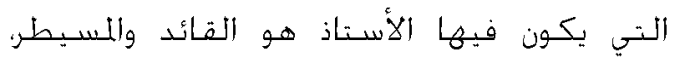
والناقل للهعرفة.

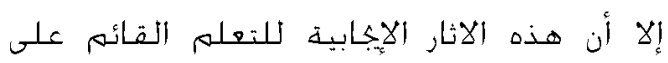

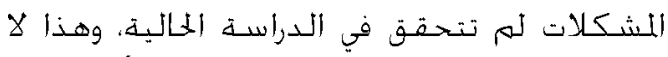

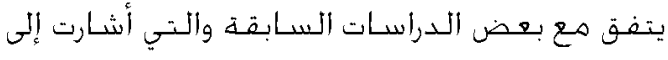

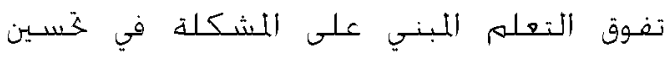
Albanse \& Mictchell, ) كتساب الطلاب للمعارف 1993; Aspy, Aspy, \& Quinby, 1993; Lambros,

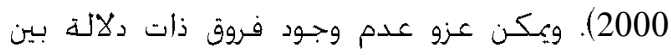

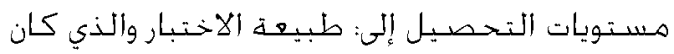

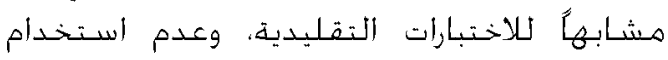

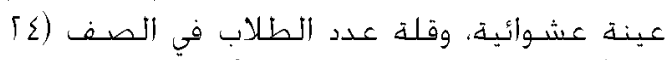

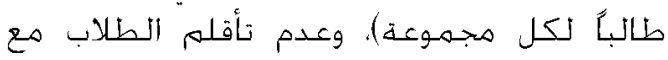

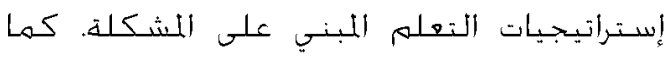

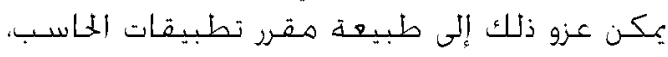

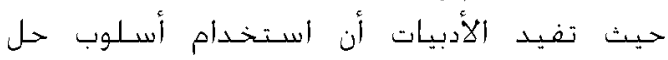

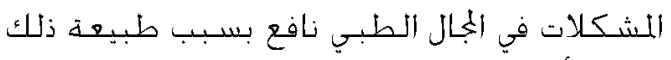

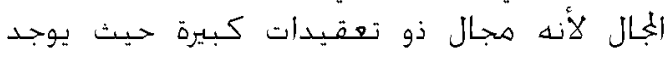

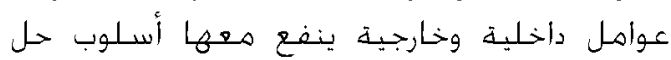

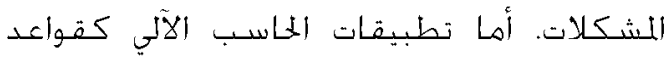

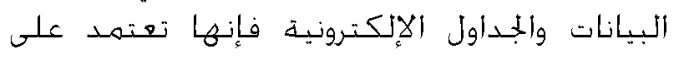

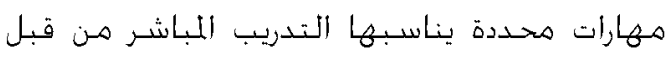

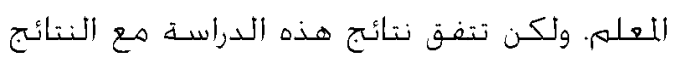

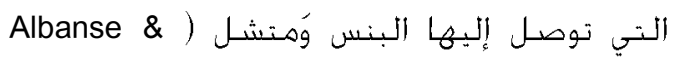
Vernon \& Blake, ) و فرنون وَبليك (Mitchell, 1993

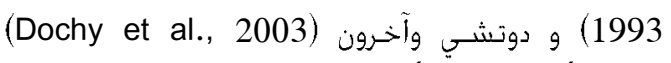

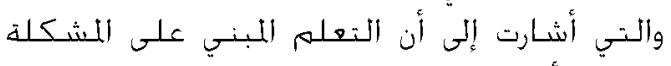
ليس لكه أثر على خَسين إداء أن الطعلاب.

فوفقًا لبيلهوت (Belhot, 1999) وَشَمهمدت فإنه عند تعرض طلاب قد اعتادوا (Shmidt, 1993)

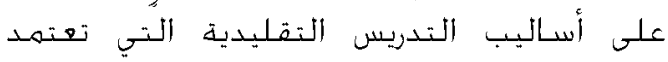

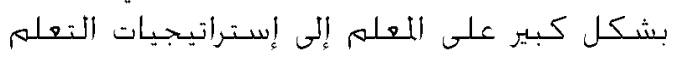

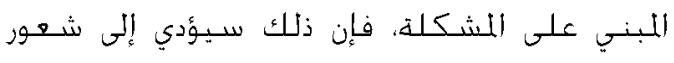

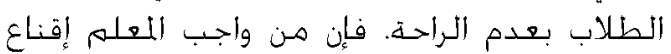

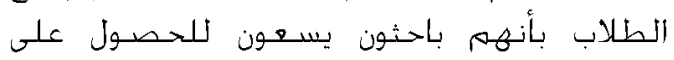

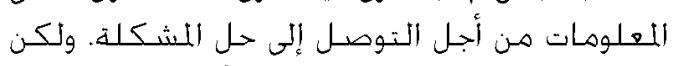

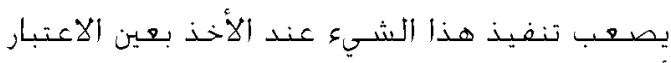

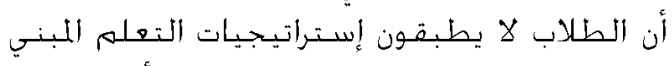

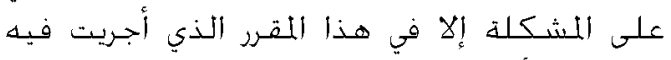

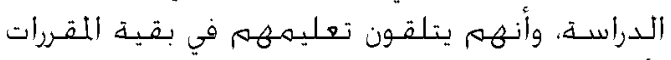
بأساليب التدريس التقليدية. 
اللشكلات التي تعرض عليهم ذات علاقة

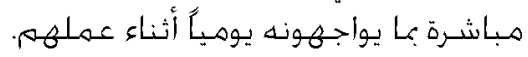

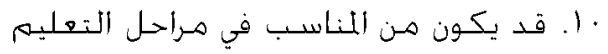

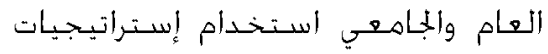

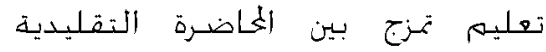

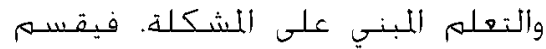

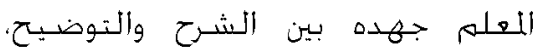

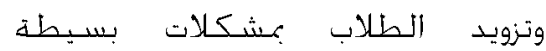
يتهاونون فيما بينهم لأجـل حلها.

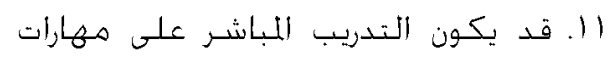

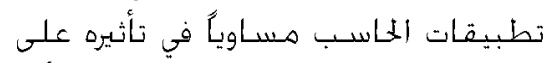

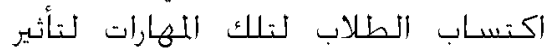

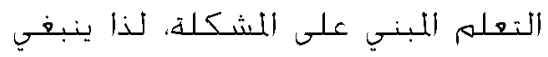

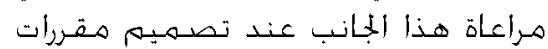
الخاسب الآي.

$$
\text { المراجع }
$$

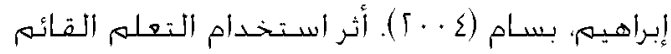

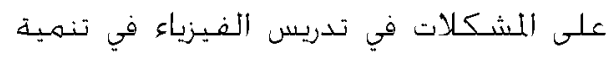

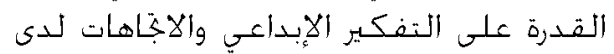

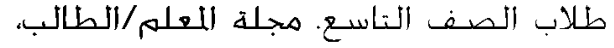
. $\int-\varepsilon .1$

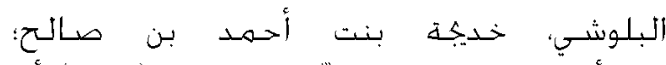

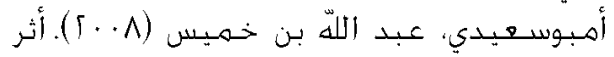

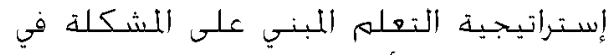

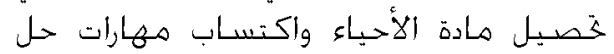

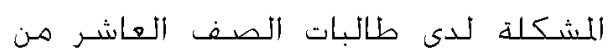

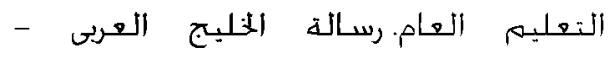

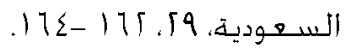

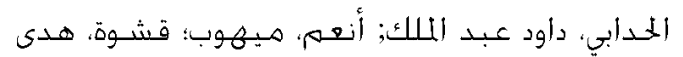

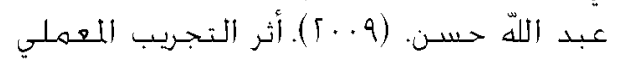

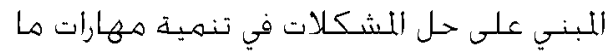

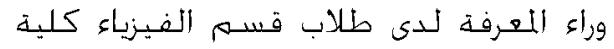
التربية - جامعة صنعاء. مجلة الدرفئة الدراسات

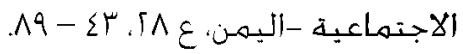

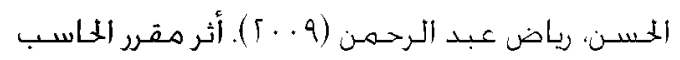

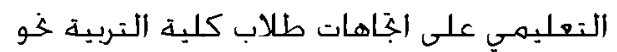

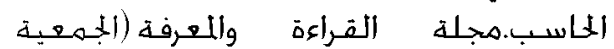

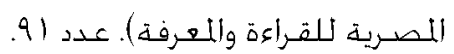

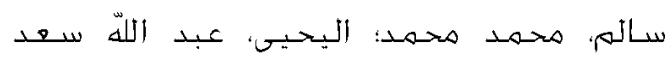

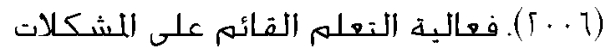

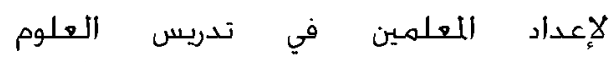

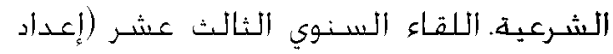

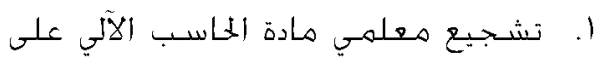

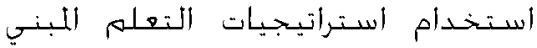
على المشكلة في تدريسهـهم.

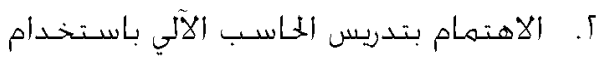

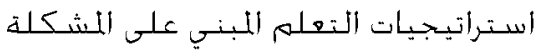

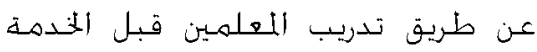

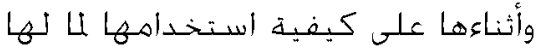

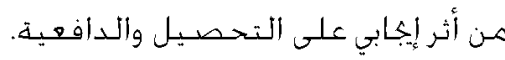

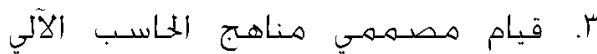

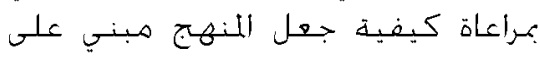

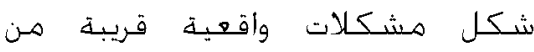

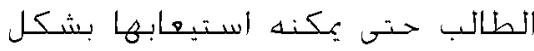

ـ. يوهـى بإجـراء دراســة مـاثلة على عينة أكـبر

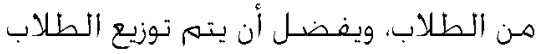

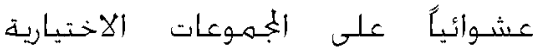

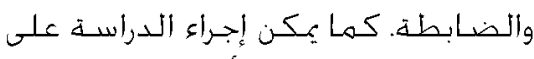

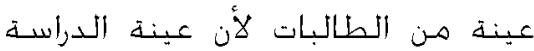

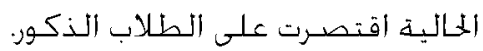

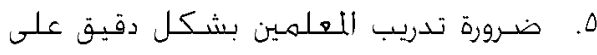

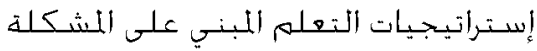

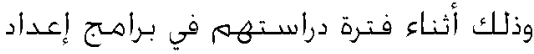
اللملهمن وذن.

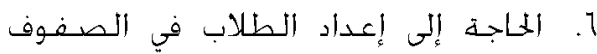

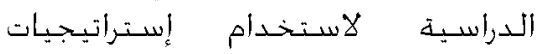

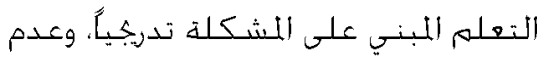

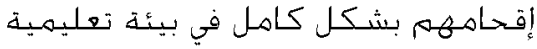
تهتمد على المشكلة.

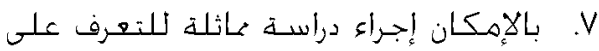

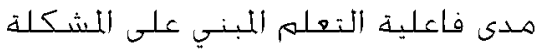

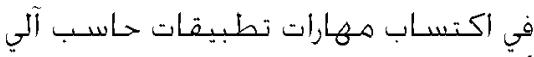

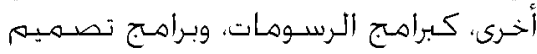

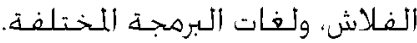

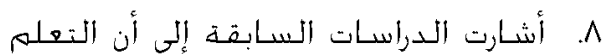

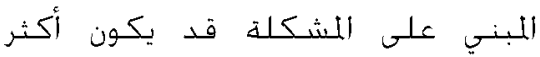

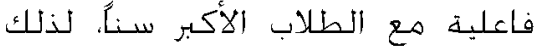

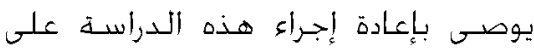

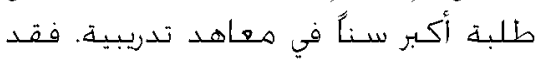

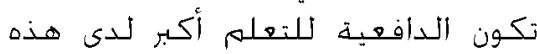
العينة من المتهلمـين.

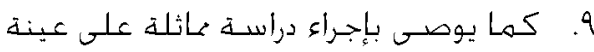

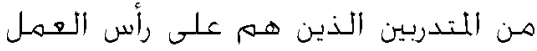

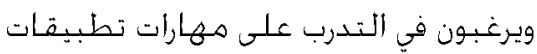

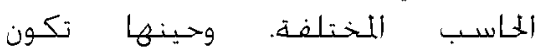


Albanse, M. A., \& Mitchell, S. (1993). Problembased learning: A review of literature on its outcomes and implementation issues. Academic Medicine, 68(1), 52-81.

Allen, D., Duch, B., \& Grosh, S. (1996). The power of problem-based learning in teaching introductory science course. New directions for teaching and learning, 68, 43-52.

Aspy, D. N., Aspy, C. B., \& Quinby, P. M. (1993). What doctors can teach teachers about problem-based learning. Educational Leadership, 4, 22-24.

Barrows, H. S. (1996). What your tutor may never tell you. A guide for medical students in problem-based learning. Springfield, IL: Southern Illinois University School of Medicine.

Belhot, R. V. (1999). An analysis of engineering education using service concepts. Paper presented at the 1999 International Conference on Engineering Education, Prague, Czech Republic.

Birgegard, G., \& Lindquist, U. (1998). Changes to students attitudes in medical school after the introduction of problem-based learning in spite of low ratings. Medical Education, 32(2), 46-49.

Blumberg, P., \& Michael, J. (1992). Development of self-directed learning behaviors in partially teacher-directed problem-based learning curriculum. Teaching and learning in medicine, 4(1), 3-8.

Boud, D., \& Feletti, G. (1991). The challenge of problem-based learning. New York: ST. Martin's Press.

Dunlap, J. (2005). Problem-based learning and self-efficacy: How acapstone course prepare students for a profession. Educational Technology Research and Development, 53(1), 65-85.

Edmondson, K. (1995). Promoting self-directed learning in developing in poor defined subject areas: a problem-based course in biology. Learning and instruction, 12(2), 189212.

Hmeol, C. (2004). Problem-based learning: what and how students learn? Educational Psychology Review, 16(3), 235-266.

Jones, B. F., Rasmussen, C., \& Moffitt, M. (1997). Real-life problem solving.

Washington, DC: American Psychological Association.

Lambros, A. (2000). Healing to learn, mutuality in education. Unpublished doctoral dissertation, Wake Forest University.

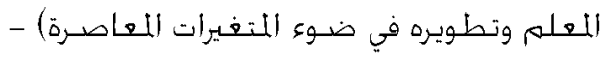

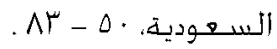

$$
\begin{aligned}
& \text { سـودي، مـنى عبد الكهادي. (199M). فاعلية } \\
& \text { استخـدام نموذج التعلم البنائي في تدريس }
\end{aligned}
$$

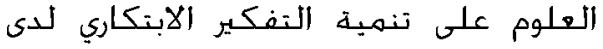

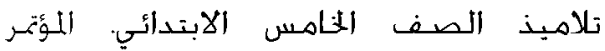

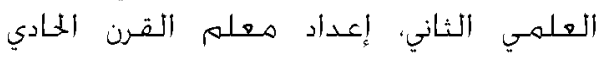

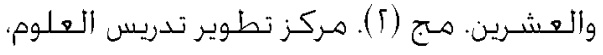

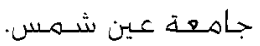

$$
\begin{aligned}
& \text { عبد الخميد، جابر (1999). استراتيجيات التدريس }
\end{aligned}
$$

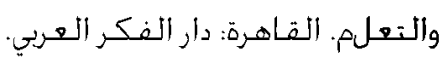

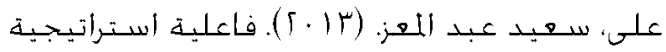

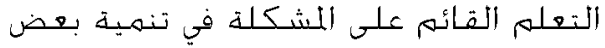

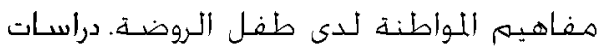

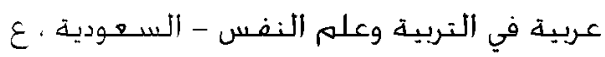

$$
\begin{aligned}
& \text { I1. - IrV.r }
\end{aligned}
$$

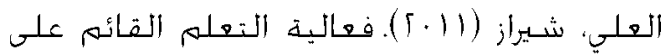

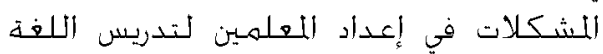

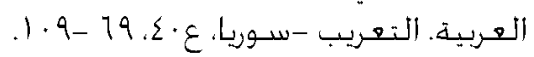

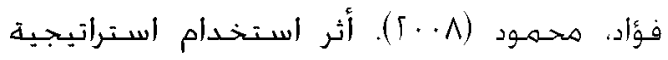

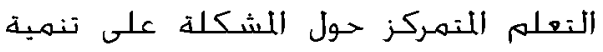

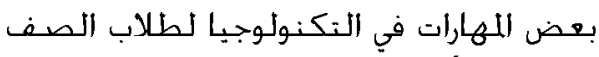

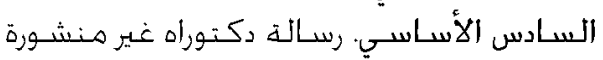

$$
\begin{aligned}
& \text { تم استرجاعها من قاعدة بيانات EduSearch. } \\
& \text { كلية التربية. غزة. }
\end{aligned}
$$


Lancaster, C., Bradely, E., Smith, I., \& Camp, M. (1997). The effect of PBL on students' perceptions of learning environment. Academic medicine, 72(10), 10-12.

Lohman, M. (2002). Cultivating problemsolving skills through problem-based approach to professional development. Human resources development quarterly, 13(3), 243-261.

Lohman, N., \& Finklestine, M. (2000). Designing groups in problem-based learning to promote problem-solving skill and self-direction. Instructional Science, 28(4), 291-307.

Marriam, S. (2001). Andragogy and selfdirected learning: Pillars of adult learning theory. New directions for adult and continuing education, (89), 3-13.

Matthews, B. (2004). The effect of direct and problem-based learning instruction in an undergraduate introductory Engineering graphics course. Unpublished doctoral dissertation. North California state university. [UMI No. 3154330].

Mennin, S., Friedman, M., Skipper, B., Kalishman, S., \& Snyder, J. (1993). Performance on the NBME by medical students in the problem-based learning and conventional tracks at the University of New Mixico. Academic Medicine, 68, 616624 .

Pederson, S. (2003). Motivational orientations in a problem-based learning environment. Journal of interactive learning research, 14(1), 51-77.

Pintrich, P. R., Smith, D. A., Garcia, T., \& McKeachie, W. J. (1993a). A Manual for the
Use of the Motivated Strategies Learning Questionnaire (MSLQ). The University of Michigan.

Pintrich, P. R., Smith, D. A., Garcia, T., \& McKeachie, W. J. (1993b). Reliability and predictive validity of the motivated strategies for learning questionnaire (MSLQ). Educational and Psychological Measurement, 53, 801-813.

Rajab, A. (2007). Effects of problem-based learning on the self-efficacy and attitudes of beginning biology majors. Unpublished doctoral dissertation. The University of California. [UMI No. 3269649].

Savery, J. R., \& Duffy, T. M. (1995). Problembased learning: an instructional model and its constructivist framework. Educational Technology, 35(5), 31-38.

Shin, J., Haynes, R. \& Johnston, M. (1993). Effect of problem-based, self-directed undergraduate education in life-log learning. Canadian Medical Association Journal, 148(6), 969-976.

Shmidt, H. (1993). Foundations of problembased learning: Some explanatory notes. Medical Education. 27, 42-49.

Speck, M. (1996). Best practice in professional development for sustained educational change. ERS Spectrum, 4(2), 33-41.

Vernon, D. T., \& Blake, R. L. (1993). Does problem-based learning work? A metaanalysis of evaluative research. Academic Medicine, 68, 550-563.

Woods, D. R. (1996). Problem-based learning: Resources to gain the most from PBL (3rd ed.). Waterdown, ON, Canada: Donald R. Woods Publisher. 